\title{
A recent trend: application of graphene in catalysis
}

\author{
Yuxin Yan ${ }^{1}$ - Woo In Shin ${ }^{2} \cdot$ Hao Chen ${ }^{1}$. Shar-Mun Lee ${ }^{1}$. Sivakumar Manickam ${ }^{2}$. Svenja Hanson ${ }^{1} \cdot$ Haitao Zhao ${ }^{3}$. \\ Edward Lester ${ }^{4} \cdot$ Tao $\mathrm{Wu}^{5,6} \cdot$ Cheng Heng Pang ${ }^{1,6}$
}

Received: 2 September 2020 / Revised: 20 October 2020 / Accepted: 22 October 2020

(c) Korean Carbon Society 2020

\begin{abstract}
Graphene, an allotrope of carbon in 2D structure, has revolutionised research, development and application in various disciplines since its successful isolation 16 years ago. The single layer of $s p^{2}$-hybridised carbon atoms brings with it a string of unrivalled characteristics at a fraction of the price of its competitors, including platinum, gold and silver. More recently, there has been a growing trend in the application of graphene in catalysis, either as metal-free catalysts, composite catalysts or as catalyst supports. The unique and extraordinary properties of graphene have rendered it useful in increasing the reactivity and selectivity of some reactions. Owing to its large surface area, outstanding adsorptivity and high compatibility with various functional groups, graphene is able to provide a whole new level of possibilities and flexibilities to design and synthesise fit-for-purpose graphene-based catalysts for specific applications. This review is focussed on the progress, mechanisms and challenges of graphene application in four main reactions, i.e., oxygen reduction reaction, water splitting, water treatment and Fischer-Tropsch synthesis. This review also summarises the advantages and drawbacks of graphene over other commonly used catalysts. Given the inherent nature of graphene, coupled with its recent accelerated advancement in the synthesis and modification processes, it is anticipated that the application of graphene in catalysis will grow exponentially from its current stage of infancy.
\end{abstract}

Keywords Catalysis · Graphene · Oxygen reduction reaction $\cdot$ Water splitting $\cdot$ Water treatment $\cdot$ Fischer-Tropsch synthesis

Cheng Heng Pang

chengheng.pang@nottingham.edu.cn

1 Faculty of Science and Engineering, University of Nottingham Ningbo China, Ningbo 315100, People's Republic of China

2 Faculty of Science and Engineering, University of Nottingham Malaysia, 43500 Semenyih, Selangor, Malaysia

3 MITMECHE, Massachusetts Institute of Technology, Cambridge, MA 02139, USA

4 Faculty of Engineering, University of Nottingham, University Park, Nottingham NG7 2RD, UK

5 Ningbo New Materials Institute, University of Nottingham, Ningbo, Ningbo 315042, People's Republic of China

6 Key Laboratory for Carbonaceous Wastes Processing and Process Intensification Research of Zhejiang Province, The University of Nottingham Ningbo China, Ningbo 315100, People's Republic of China

\section{Introduction}

Catalysis is the application of catalysts to increase the rate of reaction and/or selectivity without being consumed during the reaction. The catalyst provides an alternative reaction pathway with lower activation energy and hence increases the rate of reaction. In some cases, the catalyst modifies the reaction mechanisms altogether, leading to improved reaction selectivity. Therefore, with the same reaction conditions, catalysis can maximise the conversion of reactants whilst reducing undesired by-products and pollutants [1, 2].

In general, only small amounts of catalysts are required to carry out the reaction and spent catalysts have the potential to be regenerated and reused. With the increasing demand for higher efficiency, lower environmental impacts and better economics, catalysis has emerged as a popular option for industrial chemical processes where approximately $90 \%$ of the commercial chemical products utilise some form of catalysts during the manufacturing process [3]. This involvement is still increasing due to the amount of progress made 
in catalysis study, which, in turn, fuels further research and development of catalysis in industrial processes [4].

In general, catalysis is subdivided into two main categories, i.e., homogeneous and heterogeneous catalysis. The former being a catalytic process where catalysts and reactants coexist in the same phase, usually providing a higher reactivity and selectivity since the reactions are not limited by mass transfer [5]. However, homogeneous catalysis is accompanied by the practical challenge of effectively separating the spent catalysts from products/unreacted reactants after the reaction. The latter, on the contrary, is a process where catalysts and reactants exist in different phases. Although such a configuration leads to a smaller contact area with active sites [6], heterogeneous catalysis is widely used in industrial processes due to its ease of separation, handling and maintenance. During heterogeneous catalysis, the active species are usually embedded on a support material which provides a large surface area to increase the otherwise limited effective contact area, as well as to prevent agglomeration of catalytic particles [3].

In the past several decades, various catalytic materials have been tried and tested in an attempt to strike a balance between efficacy, efficiency and cost. Conventionally, catalysts are mostly based on rare metals, noble metals, transition metals, metal oxides and/or hybrid materials or composites with active metallic centres. However, their applications as catalysts have been limited due to the associated high costs, toxicity [7] and environmental issues [1]. Moreover, the high surface energy of metallic particles commonly leads to severe aggregation, resulting in the loss of accessible active sites, and hence catalytic activity. This, in industry, is compensated by using an even larger quantity of scarce and depleting metals with more detrimental impacts on the environment. Hence, there is a need to explore potential alternatives with higher efficiency, lower costs and better sustainability in the efforts to relieve the dependency on metallic resources $[1,4,7]$.

As alternatives to the materials currently used in catalysis, various carbon-based materials have been explored as forms of metal-free catalysts or catalyst supports. This is partially due to its abundance in nature, low cost and reduced negative impacts on the environment [8]. Carbon-based materials are also known to uphold high stability in acidic and basic conditions compared to commonly used materials, such as silica and zeolite. These characteristics are what make carbon-based catalysts highly desirable as an alternative in a wide range of industrial processes.

In this study, the main carbon-based material that will be focused on is graphene, a monolayer of hexagonally arrayed carbon atoms with a large theoretical surface area of approximately $2630 \mathrm{~m}^{2} \mathrm{~g}^{-1}$ [9-11]. Graphene is also known to have strong chemical resistance, high thermal stability, convenient recovery of active phase [12] and good dispersibility
[13], thus making it extremely desirable as a catalytic material. More importantly, graphene has outstanding adsorptivity, which plays a very crucial role in heterogeneous catalysis as it is the minimum requirement for reactant molecules to adsorb onto the surface active sites for reactions to take place. The easily accessible structure on both surfaces of graphene sheets would significantly reduce the time taken for reactants to diffuse to an active site. The mass transfer of reactants becomes facile without internal diffusion [14], hence increasing the reaction rate in heterogeneous catalytic processes which are mostly determined by the mass transfer or diffusion.

There are three main categories of sites on the surface of graphene, including the top $(\mathrm{T})$, hollow $(\mathrm{H})$ and bridge (B) sites (refer to Fig. 1) [15-17]. According to the density functional theory, adatoms from transition metals, such as $\mathrm{Ru}, \mathrm{Ti}, \mathrm{Fe}, \mathrm{Ni}, \mathrm{V}$ and $\mathrm{Co}$, are adsorbed stably on the hollow $(\mathrm{H})$ sites. In contrast, non-metallic elements and transition metals with nearly or completely filled d shells, such as $\mathrm{Pt}$, $\mathrm{Pd}$ and $\mathrm{Cu}$, are more stable on the bridge (B) sites. On the other hand, $\mathrm{H}, \mathrm{F}, \mathrm{Cl}, \mathrm{Br}, \mathrm{I}, \mathrm{Ag}$ and $\mathrm{Au}$ are more stable on the top (T) sites $[15,16]$. The type of adsorption that the adatoms undergo is classified into either long-range, weak van der Waals adsorption (physisorption) or short-range, strong covalent adsorption (chemisorption), depending on the properties of both the adsorbent and adsorbate. For example, adatoms of $\mathrm{Cu}$ and half-filled $\mathrm{d}$ shell transition metals, such as $\mathrm{Au}$ and $\mathrm{Ag}$, have long bond range; hence, they are expected to undergo physisorption. On the contrary, $\mathrm{Pt}, \mathrm{Pd}$ and $\mathrm{Ni}$ with short bond distances are expected to form covalent bonds with graphene with higher resistance to the adatom movement $[15,16,18]$. The hexagonally arrayed

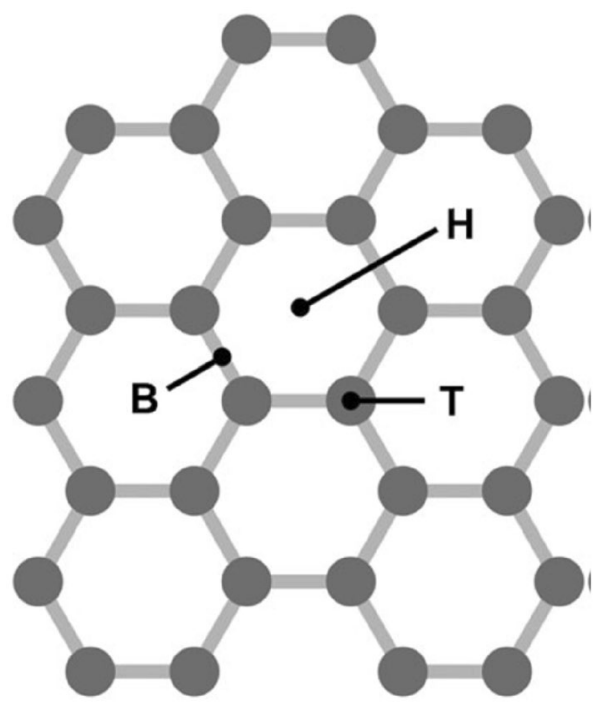

Fig. 1 Three adsorption sites of high symmetry for binding the adatom over graphene [17] 
carbon atoms in graphene are packed in two-dimensional honeycomb lattices composed of two equivalent sub-lattices of carbon atoms being bonded together by sigma bonds. The pi bonds which are formed during the hybridisation of the carbon atoms form interactions with each other between the graphene layers, thus allowing delocalised electrons to be conducted through the basal planes [19] (refer to Fig. 2). It is important to note that some properties vary considerably with both the number of layers and the stacking order [17].

In the efforts of further improving the application of graphene in heterogeneous catalysis, extensive work has been put into exploring graphene and its derivatives, such as graphene oxide (GO), reduced graphene (rGO) and doped graphene as catalytic materials [20]. The process of doping graphene structures has always played an important role in the field of catalysis. The presence of oxygen-containing functional groups in both GO and rGO provides the possibilities of further modification with other functional groups, potentially improving the solubility, dispersibility and stability of GO and rGO [3, 21, 22]. However, the presence of oxygen functional groups on the surface can cause defects in the basal plane and electron irradiation on graphene layers [23], reducing the mobility of electrons, resulting in the graphene material experiencing critical losses in terms of conductivity and catalytic activity. In order to restore and recover the lost properties, GOs are usually reduced via thermal and chemical methods [24].

Apart from having desirable properties for catalysis, graphene has also been identified to possess properties which are useful in a wide range of applications $[25,26]$ and technologies, thus prompting extensive research on graphene as well as its possible applications. The large surface area and remarkable electrical conductivity of graphene also promote its application in electrochemical reactions which, in turn, are applied in oxygen reduction reactions (ORRs) in membrane fuel cells as well as in hydrogen generation during water splitting. Also, the excellent performance of graphene in photocatalysis has fuelled its development in

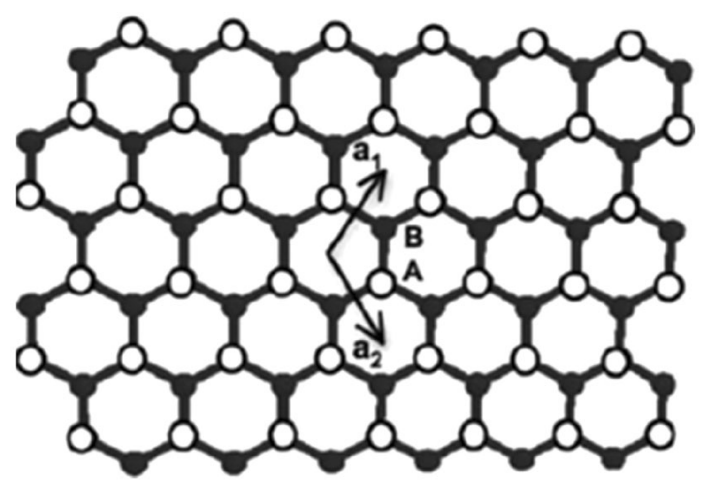

Fig. 2 Schematic crystal structure of graphene [19] water treatment and environmental engineering. Due to the uniform dispersion of catalytic metal oxide nanoparticles on graphene and its successful application in various systems, a series of work on using graphene-based catalysts in Fischer-Tropsch synthesis were reported to improve the production of hydrocarbon fuel. Hence, the use of graphene in catalysis has significant potential in contributing to the progress in clean energy technology.

Despite all of the possible applications of graphene and graphene-based materials in industrial processes, the feasibility of producing graphene at an industrial scale is yet to be established and most graphene-based catalysts, to date, are prepared at a laboratory scale. At the current stage of development, most works are focused on improving the durability and activity of the catalysts. However, the full extent of the structures, morphologies and properties of graphene and graphene-based materials can vary due to many possible parameters, such as feedstock material, reduction method, composition, the type of reducing agent, temperature and pressure. Due to the varied permutations when it comes to applying graphene and graphene-based materials, the optimisation of graphene-based materials in the field of catalysis needs to be further emphasised, explored and developed from its current stage of infancy [27, 28].

This review aims to critically understand the recent progress made in the application of graphene in catalysis. Specifically, this review characterises a series of graphenebased catalysts and supports used in four of the most popular chemical processes, i.e., oxygen reduction reaction (ORR), water splitting, water treatment and Fischer-Tropsch synthesis. The contributing factors to its successful applications, the reaction mechanisms, as well as the scalable synthesis pathways, are studied. A horizontal comparison with other commonly used metal oxide and carbon catalysts and vertical comparison with similar graphene-based and metal-free catalysts are carried out to analyse the potential and challenges of graphene in catalysis comprehensively.

\section{Oxygen reduction reaction (ORR)}

Oxygen reduction reaction (ORR) is known to be one of the most significant reactions that occur in various bioprocesses and also in systems involving energy conversion [29]. Specifically, in the development of energy technologies, polymer electrolyte membrane fuel cells with high conversion efficiency and low emission have been increasingly developed and recognised as a pivotal part of electrochemical technology. The setup of a polymer electrolyte membrane fuel cell includes an anode and a cathode electrode located separately at the two sides of an acidic or alkaline electrolyte membrane. Fuel oxidation reaction involves the oxidation of hydrogen and occurs at the anode, whilst ORR takes place at 
the cathode. There are two known pathways in which ORR occurs. The first pathway is a direct four-electron reduction pathway which directly gives rise to the formation of $\mathrm{H}_{2} \mathrm{O}$, whilst in the second pathway $\mathrm{H}_{2} \mathrm{O}_{2}$ is formed and eventually reduced to $\mathrm{H}_{2} \mathrm{O}$ [30]. The former is more favourable as it transfers four electrons per molecule [29]. On the other hand, the $\mathrm{H}_{2} \mathrm{O}_{2}$ produced in the second, the two-electron, pathway reduces the stability via degradation of the membrane and ionomer [31]. Eventually, it decreases the catalytic activity by loss of active sites. This is particularly true for transition-metal-based active sites which experience oxidative attacks [32].

In acidic fuel cells, the rate of ORR at the cathode is significantly lower than that of the oxidation of hydrogen at the anode. It, therefore, is considered an adverse, limiting effect on the overall performance of the fuel cell [32]. In order to counter this issue, a cathode catalyst (usually platinum-based) is required to boost the kinetics of the ORR to ensure rapid overall reactions of the fuel cell. In contrast, the kinetics of oxygen reduction is considerably higher in alkaline conditions, thus providing more flexibilities to utilise other less efficient, and also less costly, materials other than platinum group metals as catalysts [33].

The two main challenges faced by the application of polymer electrolyte membrane fuel cell are the high costs and low durability of the cathode ORR catalysts. The cathode ORR catalysts are generally composed of platinum and/or other rare, expensive metals, which account for approximately $50 \%$ of the material cost in fuel cells $[28,33,34]$. Although the platinum-based cathode catalysts are currently the most practical and efficient in fuel cells [35, 36], they are also affected by catalyst deactivation such as sintering, Pt dissolution and agglomeration [28]. As a result, the application of fuel cells has been limited by its high capital and maintenance costs. Potential alternatives, particularly graphene-based materials, have been progressively explored to overcome this problem.

\subsection{Graphene-based platinum catalyst}

To date, Pt or Pt-alloy catalysts remain as the most widely employed ORR catalysts for fuel cells. However, graphene is commonly introduced as a support for Pt or Pt-alloy catalysts to provide a large electrochemical surface area (ECSA). Thus, by introducing a large ECSA, oxygen diffusion on the surface of metal sites is facilitated and promoted, thus increasing the overall performance of ORR. This has been illustrated in an experiment where the reduction current on $\mathrm{Pt} / \mathrm{RG}-\mathrm{O}$ is $4.94 \mathrm{~A} \mathrm{~g}^{-1}$, significantly higher compared to 3.17 $\mathrm{A} \mathrm{g}^{-1}$ on $\mathrm{Pt} / \mathrm{C}$ when under kinetic control at a given polarised potential of $0.6 \mathrm{~V}$ [37]. However, the resisting nature of graphene makes surface deposition extremely challenging, particularly whilst depositing well-dispersed nanoparticles of platinum species and/or other metallic species of uniform size. The most popular preparation method is by interacting metal precursor solution such as $\mathrm{H}_{2} \mathrm{PtCl}_{6}$ with graphene oxide to form composite [28] as oxygen-containing functional groups on the surface of graphene oxide provide high solubility in numerous solvents. In other research works, poly(diallyldimethylammonium chloride) (PDDA) [38] and quaternary ammonia poly(2,6-dimethyl-1,4-phenylene oxide) (AEI) [39] are applied to functionalise the surface and strengthen the deposition of nanoparticles. The high concentration of functional groups reduces the electronic conductivity, thus leading to chemical reduction or thermal reduction occurring simultaneously.

Regarding the improvement in ORR performance, enlarging the ECSA has become the driving factor that influences the research direction. A significant increase in ECSA is found to be achieved as a result of optimal two-step reduction which involves the addition of $\mathrm{NaBH}_{4}$ in $\mathrm{GO}$ dispersion followed by ethylene glycol (EG) at $150{ }^{\circ} \mathrm{C}$ for $12 \mathrm{~h}$, rather than a one-step reduction where only EG is used [40]. A slight improvement in the ORR activity is also observed by two-step reduction using EG, followed by 1,2-hexadecanediol (HAD) as an additional reductant [41]. Another more effective reductant available is hydrazine. It is recommended that $\mathrm{Pt} / \mathrm{GO}$ should not be directly exposed to hydrazine to avoid stacking of graphene sheets caused by strengthened pi-pi interaction and the anchored platinum particles which will hinder the collapse. Therefore, hydrazine is only used after the partial reduction of $\mathrm{NaBH}_{4}$ on $\mathrm{Pt} / \mathrm{GO}$, followed by a heat treatment at an optimal temperature of $300{ }^{\circ} \mathrm{C}$ for $8 \mathrm{~h}$. Overall, this method of exposing $\mathrm{Pt} / \mathrm{GO}$ catalyst to hydrazine at optimal temperature was responsible for approximately $80 \%$ of the increase in ECSA. However, the practical power output measured was lower than two-step reduction Pt/GO, which is suspected to be caused by the loss of proton conductivity of the Nafion ionomer at high temperature [42]. The parameters contributing to the lower practical power output is still unclear, offering research teams potential possibilities for further enhancing ORR activity.

In experiments focusing on the comparisons of ORR performances using different catalysts compositions, it is important to keep in mind that the different sizes and morphologies of nanoparticles on the support surface which result from different synthetic methods can have significant effects on the ORR activity. Deng et al. [43], explored the ORR using various sizes of pristine graphene as catalysts for the ORR process. The graphene was formed from the exfoliation of graphite powder (GP) via ball milling to produce graphene with a nanometre size range (GP-BM) [44, 45]. From the results, it was reported that smaller size graphene has more edges, and they suggested that the bulk $s p^{2}$-hybridised carbon network itself is inactive due to the lack of defected edges 
[46]. The Raman spectroscopy showed a weak Raman $D$ band, indicating the presence of a small amount of defect edge, whilst GP-BM showed intensified $D$ and $D^{\prime}$ bands. When it was tested for electrocatalytic activity in ORR, the onset potential and current density were found to be higher for graphene of smaller size at a fixed voltage, demonstrating the relationship of performance of oxygen reduction reaction with graphene particle size, i.e., better performance with graphene of smaller size [43].

In an experiment conducted by Guo et al. [47], PtFe/G catalyst and $\mathrm{PtFe} / \mathrm{C}$ black catalysts with controlled size and morphology were prepared. From the results observed, the half-wave potential of $\mathrm{PtFe} / \mathrm{G}$ was higher than both $\mathrm{PtFe} / \mathrm{C}$ of the same size and commercial $\mathrm{Pt} / \mathrm{C}$, reinforcing the advantages of using graphene as a support rather than a series of carbon supports. From these results, two benefits of using graphene as a support are pointed out, the first advantage being that ORR activity is improved by increasing ECSA whilst reducing the mass loading of precious metals as much as possible. This is especially true in acidic conditions where platinum-based catalysts with conventional carbon support are unstable. Another benefit of using $\mathrm{PtFe} / \mathrm{G}$ that is pointed out from the experiment is the excellent electrochemical stability of the $\mathrm{PtFe} / \mathrm{G}$ as it displayed no signs of loss in activity after 10,000 potential sweeps.

Another experiment which was conducted by $\mathrm{Li}$ et al. [41] involved synthesising $\mathrm{PtM} / \mathrm{rGO}$ (where $\mathrm{M}=\mathrm{Co}$, $\mathrm{Ni}$ ) via a facile hydrothermal route to prove the superiority of using graphene support instead of commercial carbon-based supports. GO was first prepared from graphite powder via modified Hummer's method and was then dispersed in deionised water by ultrasonication. $\mathrm{Pt}$ was dissolved in ethylene glycol (EG)-water under continuous magnetic stirring and heating before dissolving $\mathrm{CO}\left(\mathrm{NO}_{3}\right)_{2} \cdot 6 \mathrm{H}_{2} \mathrm{O}$ or $\mathrm{NiSO}_{4} \cdot 6 \mathrm{H}_{2} \mathrm{O}$. 1,2-hexadecanediol was then added as additional reductant before being heated in an autoclave. Finally, the precipitate was collected and washed with ethanol and deionised water via centrifugation and dried in a vacuum. The results showed that the ECSA value of $\mathrm{PtCo} / \mathrm{rGO}\left(11.0 \mathrm{~m}^{2} \mathrm{~g}^{-1}\right)$ was lower than PtNi/rGO $\left(13.7 \mathrm{~m}^{2} \mathrm{~g}^{-1}\right)$. However, the ECSA values found for both graphene support-based catalysts are still lower than commercial Pt/C catalyst (33-55 $\mathrm{m}^{2} \mathrm{~g}^{-1}$ ), but they do exhibit higher electrochemical stability. The superiority of graphene compared to other carbon or metal oxide support has been demonstrated, and new methods for synthesising graphene-based Pt-alloy catalysts are emerging. Unfortunately, finding the optimal composition to minimise the differences in practical performance in ORR between these catalysts and to decrease expensive $\mathrm{Pt}$ usage as much as possible remains to be a challenge.

\subsection{Heteroatom doped graphene as catalyst and support}

The performance of ORR can also be improved by utilising doped graphene as a catalyst. This increase in performance is due to the introduction of various heteroatoms (e.g., N, $\mathrm{B}, \mathrm{S})[48,49]$ with different electronegativity into the graphene structure, which can disrupt the electroneutrality of graphene by polarising the $\mathrm{X}-\mathrm{C}$ bond $\mathrm{X}=\mathrm{N}, \mathrm{B}, \mathrm{S}$, etc., and creating charged sites. These positively charged sites favour the adsorption of $\mathrm{O}_{2}$, facilitating the ORR performance $[48,50]$. These heteroatoms that were introduced can also be considered as nucleation sites that encourage the well-dispersed deposition of nanoparticles in uniform size without any other surface functionalisation process. Finally, heteroatoms help prevent the loss of active sites by reducing dissolution and Ostwald ripening, helping to strengthen the interaction between doped graphene and the metal catalyst.

\subsubsection{Nitrogen-doped graphene}

$\mathrm{Pt} / \mathrm{N}$-doped graphene catalyst synthesised by $\mathrm{N}_{2}$ plasma and chemical reduction is observed to provide better performance in ORR than $\mathrm{Pt} / \mathrm{G}$ according to the polarisation graph, which is attributed to the formation of pentagonal and heptagonal structure, increasing the reactivity of carbon atoms in the vicinity. The introduction of nitrogen doping disorder and defect can facilitate the deposition of Pt particles, improving the binding energy and electrical conductivity [51]. Significant improvements are also achieved, proven by high peak current density, peak potential and durability even in the acidic condition when N-G is used as support for metal catalyst [52]. The effect of introducing nitrogen doping disorder and the defect was observed and confirmed by Jingcheng Bai et al. who noticed that $\mathrm{N}$-doped graphene possesses higher catalytic activity whether working as the support or as a metal-free catalyst in ORR. Thus, N-G, in particular, is expected to be further explored in future as a potential substitute for precious metals used in catalysts in alkaline conditions as well as to improve the kinetics of ORR in acidic conditions, as the kinetics is limited by the intermediates formed in the two-electron pathway.

\subsubsection{Phosphorous-doped graphene}

Another possible combination of doped graphene is by introducing phosphorus, which has a much lower electronegativity in comparison with carbon. In an experiment conducted by Zhang et al. [53], phosphorus-doped graphene (PG) was synthesised from graphite oxide (GO) and triphenylphosphine (TTP) via thermal annealing at different temperatures (700, 900 and $1000^{\circ} \mathrm{C}$ ). First of all, the GO was synthesised from graphite powder using the modified Hummers method. 
Then, $30 \mathrm{mg}$ of the synthesised GO was mixed with $150 \mathrm{mg}$ of TTP and $50 \mathrm{mg}$ of ethanol in an open beaker at room temperature. The ethanol was then evaporated off from the mixture by drying it in a vacuum oven overnight. Finally, the ethanol-free mixture was poured into a quartz boat located at the centre of the tube furnace to undergo annealing treatment, before collecting it when the temperature fell below $60{ }^{\circ} \mathrm{C}$. To test the electrocatalytic activity, the cyclic voltammetry $(\mathrm{CV})$ was examined. The reduction process could be observed at $0.6 \mathrm{~V}$ in $\mathrm{O}_{2}$-saturated $0.1 \mathrm{M} \mathrm{KOH}$ solution. In contrast, no obvious features were observed for the $\mathrm{N}_{2}$ condition, hence suggesting an assured electrocatalytic activity of PG towards ORR (refer to Fig. 3a). A positive onset potential and high current density of PG $(0.92 \mathrm{~V})$ that is comparable to that of commercial $\mathrm{Pt} / \mathrm{C}$ catalyst $(0.95 \mathrm{~V})$ also showed that PG facilitated the ORR (refer to Fig. 3b). To test for crossover effect, which might occur in fuel cell leading to cathode catalyst poisoning, methanol was introduced into the $\mathrm{O}_{2}$-saturated $0.1 \mathrm{M} \mathrm{KOH}$ solution. For the PG catalyst, no noticeable change could be observed. Still, Pt/C showed an instantaneous jump of current with the addition of methanol, indicating that methanol oxidation reaction (MOR) has occurred (refer to Fig. 3c). The result showed that PG has a higher tolerance towards methanol crossover compared to $\mathrm{Pt} / \mathrm{C}$.

\subsubsection{Boron-doped graphene}

Boron is another promising alternative for the doping of graphene when attempting to improve its electrochemical properties. Similar to phosphorous atoms, boron atoms have a lower electronegativity than nitrogen and carbon atoms, and the electron-deficient character of boron atoms is what attributes to B-doped carbon-based catalysts having such high catalytic activity [54]. Two such examples of experimental case studies focusing on the catalytic activity of boron-doped graphene catalysts in ORR have been found. The first example is Jang et al. and team [55] who utilised the spin-on dopant (SOD) method to fabricate boron-doped graphene by annealing graphene flakes (GF) and SOD films in an argon atmosphere at temperatures of $500{ }^{\circ} \mathrm{C}$ and $600{ }^{\circ} \mathrm{C}$ in a tube furnace (refer to Fig. 4). The Raman
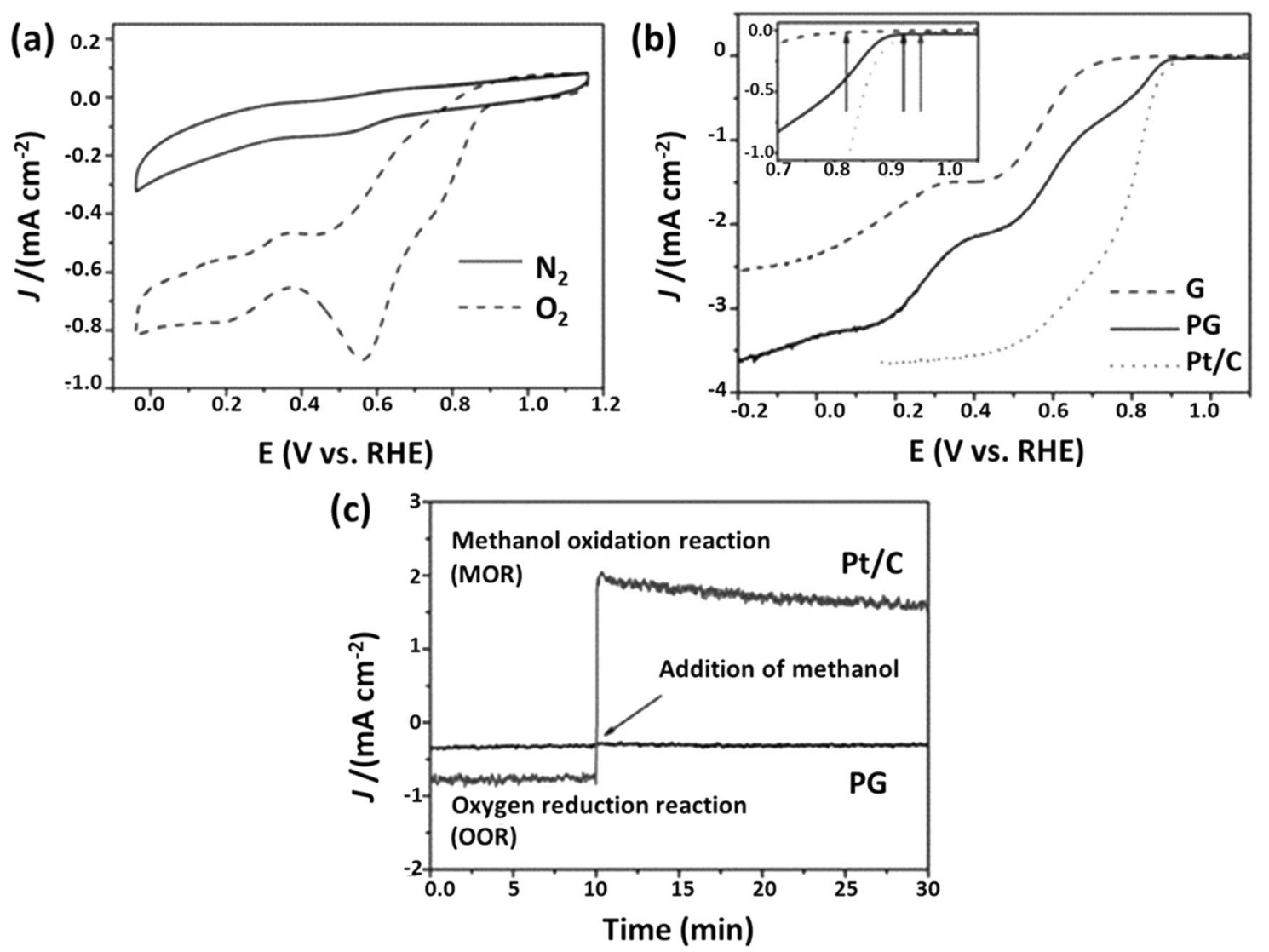

Fig. 3 a $\mathrm{CV}$ curve of $\mathrm{PG}$ in an $\mathrm{O}_{2}$ - and $\mathrm{N}_{2}$-saturated $0.1 \mathrm{M} \mathrm{KOH}$ solution with a scanning rate of $100 \mathrm{mV} \mathrm{s}^{-1}$. b Linear scanning voltammetry (LSV) curve of graphene, $\mathrm{PG}$ and $\mathrm{Pt} / \mathrm{C}$ in an $\mathrm{O}_{2}$-saturated $0.1 \mathrm{M} \mathrm{KOH}$ solution at a scanning rate of $100 \mathrm{mV} \mathrm{s}^{-1}$ and at a rota- tional speed of $1600 \mathrm{rpm}$. c Methanol crossover effect test for both $\mathrm{PG}$ and $\mathrm{Pt} / \mathrm{C}$ with the addition of methanol in an $\mathrm{O}_{2}$-saturated $0.1 \mathrm{M}$ $\mathrm{KOH}$ solution at $0.7 \mathrm{~V}$ [53] 

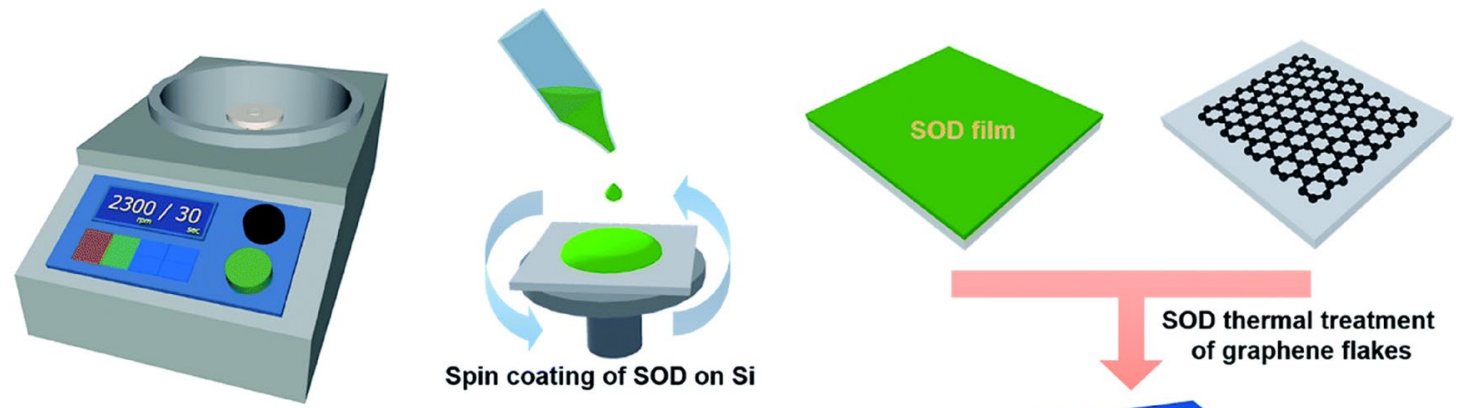

SOD thermal treatment of graphene flakes

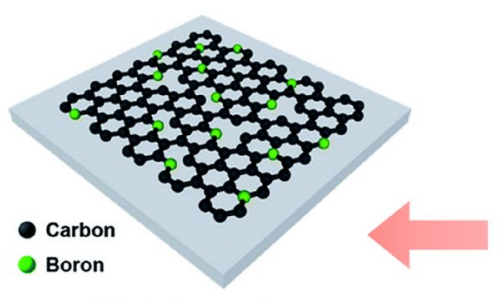

Boron doped graphene
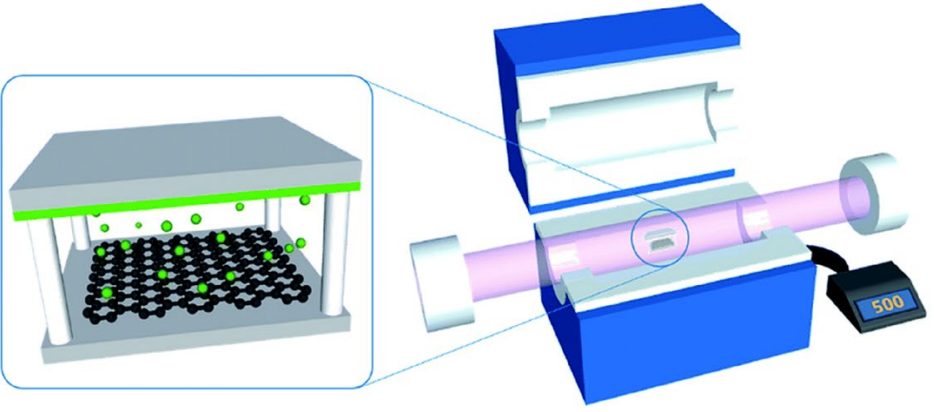

Fig. 4 Schematic diagram for the fabrication of boron-doped graphene using the SOD treatment method [55]

spectra indicated that SOD-treated GF have more defective sites in the basal plane than just GF due to the incorporation of boron atoms into the hexagonal structure which helps to improve the catalytic activity since the defects increase the overall ECSA. Furthermore, linear sweep voltammetry (LSV) measurements were carried out on both commercial Pt/C catalysts and SOD-treated GF at $600{ }^{\circ} \mathrm{C}$ in an $\mathrm{O}_{2}$-saturated $1.0 \mathrm{M} \mathrm{KOH}$ electrolyte at $1600 \mathrm{rpm}$. After 7200 s, Pt/C catalyst showed a $20 \%$ decrease in current density, whilst the SOD-treated GF at $600{ }^{\circ} \mathrm{C}$ only displayed a slight decrease to $91.4 \%$ of its initial current density as well as no further change when $1.0 \mathrm{ml}$ of methanol was added to the electrolyte. This concludes that SOD-treated GF has high electrochemical stability as well as high methanol tolerance [55]. The next experiment conducted by Bo and Guo et al. synthesised ordered mesoporous boron-doped carbon (BOMC) and compared it with commercial Pt/C catalyst as well as with ordered mesoporous carbons (OMC) when undergoing ORR in $0.1 \mathrm{M} \mathrm{KOH}$. XRD and TEM revealed that BOMC has an ordered mesoporous structure, uniform pore distribution as well as a high surface area. These desirable traits found in BOMCs makes it a cheap and highly active metal-free catalyst for ORR, especially in alkaline conditions [56].

Apart from the two studies mentioned above, the number of studies on the benefits of doping graphene with boron in the catalytic applications of ORR remains very scarce [54], making drawing a well-educated conclusion on this very difficult, despite the promising results that were displayed in the two studies. There have also been several studies on the co-doping of carbon materials with boron and other heteroatoms of higher electronegativity (mostly nitrogen), mostly giving mixed results. Zhao et al. and the team produced $\mathrm{B}$ and $\mathrm{N}$ co-doped carbon nanotubes using chemical vapour deposition (CVD) growth whilst producing $\mathrm{B}$-doped carbon nanotubes and $\mathrm{N}$-doped carbon nanotubes via post-treatment. It was shown that $\mathrm{B}$ and $\mathrm{N}$ co-doped carbon nanotubes do not affect ORR activity whilst B-doped and $\mathrm{N}$-doped carbon nanotubes improve ORR performance [57]. Contrary to this, Zheng et al. and team conducted a study comparing the catalytic activity of pure graphene, B-graphene, N-graphene, B,Ngraphene and h-BN-graphene and concluded that $\mathrm{B}$ and $\mathrm{N}$ have a synergetic effect when co-doped into graphene, producing higher catalytic activity than just individually doped N and B graphene [58]. Therefore, it is true that boron can be a potential heteroatom used for doping of graphene; however, more study on this is required.

Among all the heteroatoms mentioned above (not including co-doped graphene), nitrogen-doped graphene is still supposed to be the most active metal-free catalyst with an electrocatalytic activity found to be higher than that of $\mathrm{Pt} / \mathrm{C}$ at a certain potential. However, trace metal impurities from Hummers' method can confound the contribution of nitrogen-doped graphene, thus requiring other following techniques such as inductively coupled plasma spectroscopy to exclude interference. In conclusion, the effects of different configurations and total content for nitrogen doping are confirmed to be important. Still, they remain unclear due to the lack of illustrations on the mechanisms which are required to fully understand the crucial parameter, which is the microstructure of nitrogen doping. 


\subsection{Graphene-based non-precious metal catalyst}

Alternative catalysts consisting of non-precious metal-based materials have also been reported to provide impressive ORR performance such as silver [59, 60], cobalt [61, 62] and manganese oxide-based catalyst [63].

\subsubsection{Silver-incorporated graphene-based catalyst}

$\mathrm{Ag}$ is a less expensive metal compared to $\mathrm{Pt}$ and has a lower electronegativity compared to $\mathrm{C}$ and $\mathrm{N}$, making it a lowercost alternative for metal catalysts. Soo et al. [60] synthesised a silver-incorporated nitrogen-doped reduced graphene oxide catalyst (Ag/N-rGO) via thermal annealing of silver nitrate supported on nitrogen-doped graphene under an $\mathrm{N}_{2}$ atmosphere. The experiment was carried out by first dissolving $\mathrm{AgNO}_{3}$ in ethanol before adding it into $\mathrm{GO}$ suspension and drying in an oven at $90{ }^{\circ} \mathrm{C}$. The remains were ground and loaded into a quartz boat before inserting into the furnace in a quartz tube for thermal annealing at $900{ }^{\circ} \mathrm{C}$ under $\mathrm{N}_{2}$ flow for an hour.

Zhou et al. [64] suggested that the $\mathrm{Ag}-\mathrm{N}$ bonding induces a more positive charge on the adjacent $\mathrm{C}$ to $\mathrm{N}$, which facilitates the adsorption of $\mathrm{O}_{2}$ and effectively reduces it. The calculation for kinetic current density $\left(J_{\mathrm{k}}\right)$ and number of electrons were calculated based on Eqs. (1) and (2) where $n$ is the overall electron transfer number, $F$ is the Faraday's constant, $K$ is the kinetic rate constant for the catalytic reaction, $C_{\mathrm{O}_{2}}$ is the dissolved oxygen concentration, $D_{\mathrm{O}_{2}}$ is the diffusion coefficient of oxygen, $v$ is the viscosity of the solution and $\omega$ is the rotation rate. The calculations deduced from the equations indicated that the value of $\mathrm{n}$ was close to 4 , indicating that the four-electron pathway is the dominant reaction. A higher $J_{\mathrm{k}}$ was also found from $\mathrm{Ag} / \mathrm{N}-\mathrm{rGO}$, and RRDE measurement showed that the onset potential of $\mathrm{Ag} / \mathrm{N}-\mathrm{rGO}$ was more positive than $\mathrm{Ag} / \mathrm{rGO}$, indicating that the ORR occurs more readily on the $\mathrm{Ag} / \mathrm{N}-\mathrm{rGO}$ surface. Also, $\mathrm{Ag} / \mathrm{N}$ rGO displays high diffusion-limited current density which is shown by the more rapid mass transfer of $\mathrm{O}_{2}$ molecules from the diffusion boundary layer to the surface of the electrode. This proves that incorporating silver into the structure results in a superior alternative on top of the fact that the $\mathrm{N}$-doped graphene performance has already been recognised above. The enhanced catalytic effect observed was stated to be due to the co-catalytic effect of the dispersed Ag nanoparticles supported on the N-rGO surface. When tested for methanol crossover, it demonstrated a better methanol tolerance compared to $\mathrm{Pt} / \mathrm{C}$ in the methanol fuel cell. Even though the onset potential of $\mathrm{Ag} / \mathrm{N}-\mathrm{rGO}$ was claimed to be lower than $\mathrm{Pt} / \mathrm{C}$ for ORR in alkaline media, it is regarded as a potential candidate to replace $\mathrm{Pt} / \mathrm{C}$ in ORR due to the consideration of economic issues, facile synthesis method [65-67] and relatively acceptable catalytic activity.
$\frac{1}{J}=\frac{1}{J_{\text {kinetic }}}+\frac{1}{J_{\text {lev }}}$

$J_{\mathrm{k}}=0.62 n F C_{\mathrm{O}_{2}} D_{\mathrm{O}_{2}}^{\frac{2}{3}} v^{\frac{1}{6}} \omega^{\frac{1}{2}}$.

\subsubsection{Cobalt-incorporated graphene-based catalyst}

As another possible alternative for graphene-based nonprecious metal catalyst, Jiang et al. [61] synthesised cobaltand nitrogen-co-functionalised graphene $(\mathrm{Co}-\mathrm{N}-\mathrm{GN})$ via thermal annealing treatment of graphene oxide/polypyrrole (GO/PPy) with the support of cobalt(II) nitrate. The electrocatalytic properties were then assessed with the aid of a CV curve. ORR was carried out using $\mathrm{Co}-\mathrm{N}-\mathrm{GN}$ as a catalyst until it reached the point where the electrolyte was saturated with $\mathrm{O}_{2}$, displaying a reduction peak of $-0.185 \mathrm{~V}$. This reduction peak is close to that produced when using commercial $\mathrm{Pt} / \mathrm{C}(-0.140 \mathrm{~V})$ and is also more positive than the Co-PPy $(-0.299 \mathrm{~V})$ and N-GN $(-0.263 \mathrm{~V})$. The onset potential of Co-N-GN is $-0.098 \mathrm{~V}$, approximate to that of $\mathrm{Pt} / \mathrm{C}$ as $-0.062 \mathrm{~V}$, coupled with the fact that peak current of $\mathrm{Co}-\mathrm{N}-\mathrm{GN}$ is even higher, hence increasing its competitiveness in alkaline ORR. The enhanced $\mathrm{Co}-\mathrm{N}-\mathrm{GN}$ catalytic properties were most likely due to the doping of $\mathrm{N}$ atoms [68] and co-functionalisation on graphene [69]. Finally, to establish the catalytic pathway of ORR in the presence of $\mathrm{Co}-\mathrm{N}-\mathrm{GN}, \mathrm{RRDE}$ measurements were used to track the formation of $\mathrm{H}_{2} \mathrm{O}_{2}$ species during ORR. It was found that $\mathrm{Co}-\mathrm{N}-\mathrm{GN}$ leads to a lower yield of hydrogen peroxide compared to N-GN and Co-PPy electrodes, indicating high ORR efficiency.

In general, the catalyst demonstrated an enhanced electrocatalytic activity with long service life and high stability for four-electron pathway ORR in an alkaline fuel cell as well as a lower resistance for electron transfer, as indicated by the electrochemical impedance spectra (EIS). Similarly, the Co/ CoO-G was confirmed by Guo et al. [70] to possess the comparable activity and better stability than commercial Pt/G. It was claimed that the dispersion of $\mathrm{CoO} / \mathrm{Co}$ nanoparticles on GN could contribute electrocatalytic activity to the ORR and by addition of $\mathrm{Me}_{3} \mathrm{NO}$; the thickness of $\mathrm{CoO}$ can be tuned to optimise the performance of catalysis when reaching $1 \mathrm{~nm}$.

Utilising the facilitation of both reduction and doping, Liang et al. [71] improved the $\mathrm{Co}_{3} \mathrm{O}_{4} / \mathrm{G}$ by synthesising the covalent hybrid $\mathrm{MnCo}_{2} \mathrm{O}_{4} / \mathrm{N}-\mathrm{rGO}$. This was done by reacting a mixture of $\mathrm{Co}(\mathrm{OAC})_{2} / \mathrm{Mn}(\mathrm{OAC})_{2}$, GO/ethanol and $\mathrm{NH}_{4} \mathrm{OH}$ at $80^{\circ} \mathrm{C}$ for $20 \mathrm{~h}$, followed by processing at $150{ }^{\circ} \mathrm{C}$ for $3 \mathrm{~h}$. RRDE measurement showed an average electron transfer of 3.9 (approximate to 4) at $0.9 \mathrm{~V}$ and $0.5 \mathrm{~V}$ using reversible hydrogen electrode (RHE). With the aid of a CV curve, a peak potential of only $20 \mathrm{mV}$ was observed between 
the hybrid and Pt/C. The current density of the hybrid catalyst even exceeded that of $\mathrm{Pt} / \mathrm{C}$ when potential fell below $0.75 \mathrm{~V}$ using RHE. The X-ray near-edge structure (XANES) measurements revealed that both the metal-O-C and metal$\mathrm{N}-\mathrm{C}$ covalent bonds on the surface result in higher activity and stability. Furthermore, the coordination of $\mathrm{Mn}$ to $\mathrm{Co}$ found that the spinel structure of the catalyst results from the substitution of $\mathrm{Mn}^{3+}$ for $\mathrm{Co}^{3+}$ in the oxide that possesses higher catalytic activity and active sites.

\subsubsection{Iron-incorporated graphene-based catalyst}

Iron- and nitrogen-co-functionalised graphene can serve as another more durable option for a non-precious metal catalyst for ORR in fuel cell batteries to replace the currently trending but costly platinum catalyst option. In a study conducted by Sibul et al. and team [72], the physical characteristics as well as ORR activity in acidic and alkaline conditions of undoped graphene $(\mathrm{G})$, undoped graphene oxide (GO), iron and nitrogen co-doped graphene ( $\mathrm{Fe}-\mathrm{N}-\mathrm{Gra})$ and iron and nitrogen co-doped graphene oxide (Fe-N-GO) were studied. The iron and nitrogen co-doped catalysts were synthesised by first mixing $100 \mathrm{mg}$ of graphene nanoplate aggregates or GO, $25 \mathrm{mg}$ of 1,10-phenanthroline, $8.3 \mathrm{mg}$ of iron(II) acetate and $10 \mathrm{mg}$ of polyvinylpyrrolidone. Then, the mixture was dispersed into Milli-Q water and ethanol at a 3:1 ratio and sonicated for $2 \mathrm{~h}$. Finally, the solution was dried under vacuum conditions and pyrolysed in a preheated furnace at $800{ }^{\circ} \mathrm{C}$ for $1 \mathrm{~h}$ under flowing $\mathrm{N}_{2}$ atmosphere.

XPS analysis on the $\mathrm{Fe}-\mathrm{N}-\mathrm{G}$ and $\mathrm{Fe}-\mathrm{N}-\mathrm{GO}$ catalysts samples synthesised displayed $\mathrm{N} 1 \mathrm{~s}$ and $\mathrm{Fe} 2 \mathrm{p}$ peaks, affirming the successful doping of $\mathrm{N}$ and $\mathrm{Fe}$ into the graphene structure. SEM secondary electron images of $\mathrm{Fe}-\mathrm{N}-\mathrm{Gra}$ and $\mathrm{Fe}-\mathrm{N}-\mathrm{GO}$ showed a reduction in particle size as well as the porosity and ECSA, with $\mathrm{Fe}-\mathrm{N}-\mathrm{GO}$ having an ECSA of $69 \mathrm{~m}^{2} \mathrm{~g}^{-1}$. At the same time, $\mathrm{Fe}-\mathrm{N}-\mathrm{G}$ displayed a much larger ECSA of $426 \mathrm{~m}^{2} \mathrm{~g}^{-1}$. This drop-in ECSA is thought to have been caused by the clogging or filling of the pores by the modifier as well as the addition of carbonaceous material which contributes to the total weight of the catalyst but not necessarily the porosity. Finally, the Raman spectroscopy showed that the physical structure of $\mathrm{Fe}-\mathrm{N}-\mathrm{Gra}$ and $\mathrm{Fe}-\mathrm{N}$ $\mathrm{GO}$ was amorphous and the surface of the graphene layers was damaged, which could be identified by the detection of a $D^{\prime}$ band at around $1610 \mathrm{~cm}^{-1}$ [72].

A half-cell experiment in both acid and alkaline conditions was conducted using a rotating disc electrode (RDE). In alkaline medium, the $\mathrm{n}$ value for the undoped Gra and GO was found to be between 2 and 4 in the potential range of 0.5 to $-0.2 \mathrm{~V}$, indicating that a two-step ORR process takes place, which is not favourable in fuel cell applications as explained in previous sections. The $\mathrm{n}$ value for $\mathrm{Fe}-\mathrm{N}-\mathrm{GO}$ and $\mathrm{Fe}-\mathrm{N}-\mathrm{Gra}$ was found to be approximately 3.5 and greater than 4, respectively. This shows that using $\mathrm{Fe}-\mathrm{N}-\mathrm{GO}$-based catalyst may host a two- or one-step process, whilst Fe-NGra-based catalyst hosts a direct one-step process without forming $\mathrm{H}_{2} \mathrm{O}_{2}$ intermediate. This in itself is sufficient to prove that $\mathrm{Fe}-\mathrm{N}-\mathrm{Gra}$ and $\mathrm{Fe}-\mathrm{N}-\mathrm{GO}$ are the superior options compared to their parent materials. Next, to find out whether $\mathrm{Fe}-\mathrm{N}-\mathrm{Gra}$ or $\mathrm{Fe}-\mathrm{N}-\mathrm{GO}$ is the better option for ORR, their respective polarisation curves and ORR parameters were found. $\mathrm{Fe}-\mathrm{N}-\mathrm{Gra}$ was found to have a greater onset potential than $\mathrm{Fe}-\mathrm{N}-\mathrm{GO}$, indicating better ORR performance. This was thought to be due to the higher concentration of $\mathrm{Fe}-\mathrm{N}_{\mathrm{x}} /$ amines in $\mathrm{Fe}-\mathrm{N}-\mathrm{Gra}$, which is known to increase the ORR activity in transition metal- and nitrogen-doped catalysts. Also, since oxygen can lower the turnover frequency of $\mathrm{Fe}-\mathrm{N}_{\mathrm{x}} /$ amine sites, $\mathrm{Fe}-\mathrm{N}-\mathrm{Gra}$, which also has a lower oxygen concentration as well as larger ECSA compared to $\mathrm{Fe}-\mathrm{N}-\mathrm{GO}$, is bound to display better electrocatalytic activity. Similar trends were observed in acidic conditions, just that the onset potential of $\mathrm{Fe}-\mathrm{N}-\mathrm{Gra}$ was lower in an acidic condition which might be due to the lower amount of graphitic nitrogen form and partial demetallation of Fe-based active sites [72].

In conclusion, it is believed that the nature of the graphene-based catalysts mentioned above directly affects their properties. This knowledge has deemed it possible for researchers to review a series of graphene-based transition metal oxides and tailor the properties of graphene by doping, incorporating functional species and controlling the morphology and structure to improve the ORR activity [73].

\section{Water splitting}

With the Earth's major non-sustainable energy supplies such as coal, natural gas and oil on the brink of depletion, the consistently increasing demand for energy will eventually drive humanity to seek much cleaner and more sustainable alternatives for energy [74]. On top of that, a renewable yet sustainable energy system to supply energy for the present without hindering the ability of future generations to meet their needs must be explored [75]. Recently, great interests and efforts have been placed on the development of hydrogen as a potential energy vector as it is energy efficient yet clean and abundant in nature. It has also been widely employed as fuel because of the high energy yield, pollutionfree emission and conveniently storable features [76, 77].

Thus, water splitting techniques have been developed, promising sustainable methods for generating solar hydrogen from water [78, 79]. Photocatalytic water splitting is categorised into two types, namely photochemical cell reaction whereby light energy is directly used to carry out the chemical reaction (refer to Fig. 5a) and photoelectrochemical cell reaction which is similar to the former but with the presence 


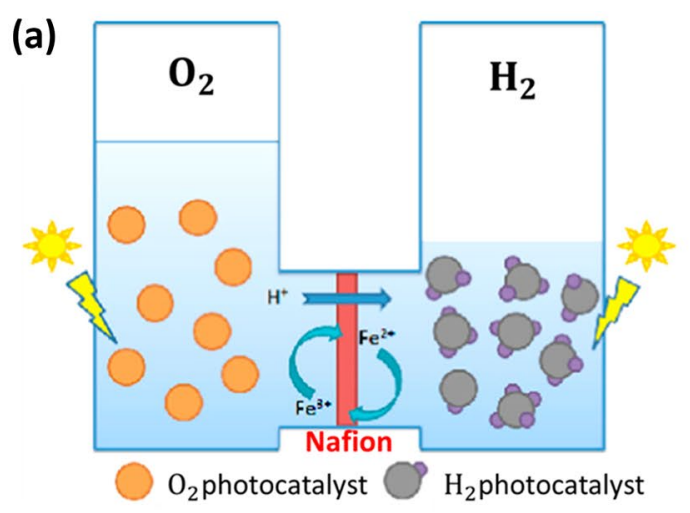

Fig. 5 a Example of a photochemical cell reaction. b Example of photoelectrochemical reaction for water with $\mathrm{TiO}_{2}$ as photocatalyst. Photogenerated electron from the photoanode is directed to the cath-

of electric current flowing through an external circuit in the system [80] (refer to Fig. 5b). These methods of photochemical reaction with photocatalyst suspended as particles in the solution are advantages in terms of the suitability in large, industrialised scale. However, controlling the powdered photocatalyst system has proven to be a challenge due to the light absorbency, instantaneous substrate concentration and $\mathrm{pH}$ change, which give rise to difficulties in finding reliable catalyst materials [81].

In the photoelectrochemical water splitting, the materials that satisfy the requirements for both oxidation and reduction are very scarce. So to carry out the separation of hydrogen evolved from oxygen, the Z-scheme photocatalyst system has to be applied. At absolute zero conditions, the conduction band (CB) of the semiconductor with higher energy level first starts empty, whilst the valence band (VB) with lower energy level is completely occupied by electrons. In the Z-scheme photocatalyst system, the semiconductor will absorb the emitted photons with energies greater or equivalent to that of the band gap energy $\left(E_{\mathrm{g}}\right)$, leading to the excitation of electrons in the VB and finally causing them to leave and fill up the holes of the CB [82] (refer to Fig. 6). The now oxidative holes $(\mathrm{h}+$ ) and reductive electrons (e-) will be able to take part in a redox reaction (as shown in Eqs. (3), (4) and (5)):

$\begin{array}{lll}\text { Oxidation: } \mathrm{H}_{2} \mathrm{O}+2 \mathrm{~h}^{+} & \longrightarrow & 2 \mathrm{H}^{+}+1 / 2 \mathrm{O}_{2} \\ \text { Reduction: } 2 \mathrm{H}^{+}+2 \mathrm{e}^{-} & \longrightarrow & \mathrm{H}_{2} \\ \text { Overall reaction: } \mathrm{H}_{2} \mathrm{O} & \longrightarrow & \mathrm{H}_{2}+1 / 2 \mathrm{O}_{2}\end{array}$

The standard Gibbs free energy change of water splitting reaction is $1.23 \mathrm{eV}$ and remains relatively constant ode via the external circuit. Oxygen produced at the anode and electron produced from the reaction of $\mathrm{TiO}_{2}$ catalyst react with the proton at the cathode producing hydrogen molecules [80]

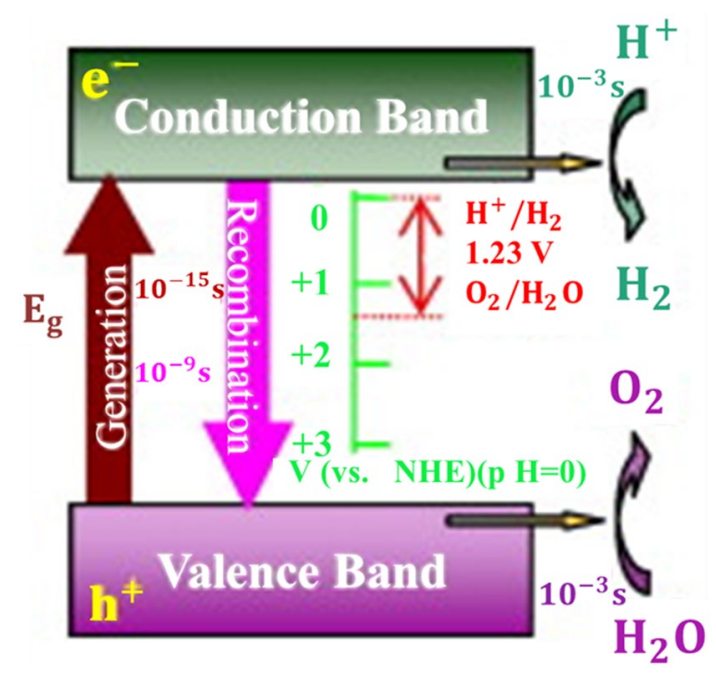

Fig. 6 Principle of photocatalytic water splitting. The bottom of the conduction band should always be located more negative than the potential of $\mathrm{H}^{+}$to $\mathrm{H}_{2}$ for $\mathrm{H}_{2}$ production. In contrast, the top of the valence band should be more positive than the oxidation potential of $\mathrm{H}_{2} \mathrm{O}$ to $\mathrm{O}_{2}$ for $\mathrm{O}_{2}$ formation [76]

regardless of the potential shift in solution $\mathrm{pH}$ [76]. Hence, to get the electrons in the VB excited by the irradiation of visible light, the theoretical minimum $E_{\mathrm{g}}$ of semiconductor photocatalyst materials should be greater than $1.23 \mathrm{eV}$. However, the value of $E_{\mathrm{g}}$ has to be below $3.0 \mathrm{eV}$ for the electrons to get excited, giving the ideal range for $E_{\mathrm{g}}$ between 1.23 and $3.0 \mathrm{eV}$ [82].

1. The pivotal requirements for photocatalytic water splitting are summarised as follows [83-86].

2. The ideal band gap is approximately $2.0 \mathrm{eV}$.

3. The redox potential should be positioned between the conduction band minimum (CBM) and valence band maximum (VBM). 
4. A large potential difference between VBM (CBM) and water oxidation (reduction) for strong oxidising (reducing) power.

5. Large active sites on the surface

6. The ability of photocatalyst to overcome recombination of photoinduced charge carrier.

\subsection{Graphene oxide photocatalyst}

GO is an easily processible, electrically insulating material that consists of a large number of $\mathrm{C}-\mathrm{O}$ bonds. $\mathrm{GO}$ is demonstrated as the initial stage when synthesising a range of substrates such as rGO, functionalised GO, doped GO and GO-based nanocomposites via different processes such as chemical or thermal reduction techniques, making it an attractive option for high yield manufacturing of graphenebased electronic devices [87]. Jiang and co-worker [88] suggested GO to be a potential photocatalytic material in water splitting since it could be produced by chemical oxidation which is both economical and easily scalable. The Pi-conjugation structure with mobility of charge carriers up to $200,000 \mathrm{~cm}^{2} \mathrm{~V}^{-1} \mathrm{~s}^{-1}$ and excellent conductivity also ensures the feasibility of GO acting as a co-catalyst in water splitting.

Yeh et al. [89] identified the characteristic of GO electronic band by determining its Fermi level potentials $\left(E_{\mathrm{f}}\right)$ via electrochemical impedance spectroscopic analysis and Mott-Schottky equation [89]. The results showed GO to have a suitable potential level of conduction and valence bands for the oxidation and reduction of water under UV and visible light irradiation in terms of the band gap requirement mentioned above. Jiang et al. [88] claimed that GO with an electronic structure of $50 \%$ coverage and $\mathrm{OH} / \mathrm{O}$ ratio of 1:1 possesses the highest efficiency for photocatalysis via visible light. The tunability of the ratio of $s p^{2} / s p^{3}$ allows the transformation of GO from an insulator to a semiconductor and graphene-like semimetal [90]. The band gap can also be tuned by the variation in oxidation level [91], hence altering the coverage of $-\mathrm{OH}$ (hydroxyl) and -O-(epoxy) functional group.

The electronic properties of GO are examined by plotting the total density of states (TDOS) on GO sheets with $\mathrm{OH} / \mathrm{O}$ ratio of 1:1 but with different percentage coverage. The results demonstrated a clean band gap (refer to Fig. 7) which is a good indication as it shows that GO avoids recombination of electron holes which improves the photocatalytic activity [92]. Another determining factor is the work function (WF), which increases with percentage coverage, shifting the VBM to the more positive side, which is favourable. Pristine graphene was found to have a work function of $4.4 \mathrm{eV}$. In contrast, graphene sheet with $100 \%$ coverage of epoxy functional group and hydroxyl functional group displayed a work function of $8.03 \mathrm{eV}$ and $5.505 \mathrm{eV}$, respectively

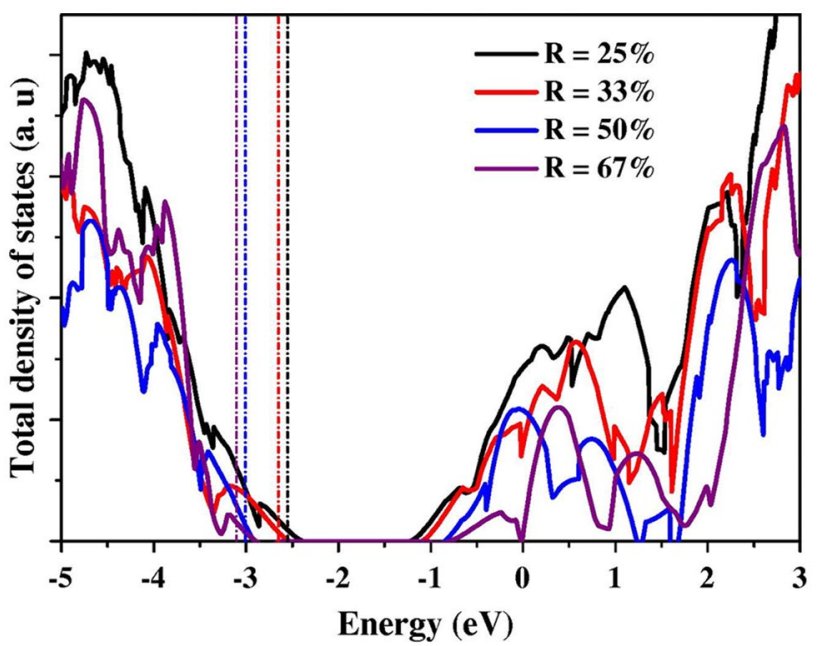

Fig. 7 Clean band gap is shown from the total density of states (TDOS) of GO for the variation of percentage coverage $(R)$ with $\mathrm{OH} / \mathrm{O}$ ratio of 1:1 [88]

Table $1 \mathrm{OH} / \mathrm{O}$ ratio, percentage coverage $(R)$, work function (WF) and band gap energy $\left(E_{\mathrm{g}}\right)$ of different GO compounds [88]

\begin{tabular}{lllll}
\hline Compounds & $\mathrm{OH} / \mathrm{O}$ & $R(\%)$ & $\mathrm{WF}(\mathrm{eV})$ & $E_{\mathrm{g}}(\mathrm{eV})$ \\
\hline Graphene & - & 0 & 4.40 & 0 \\
$\mathrm{C}_{8} \mathrm{O}_{4}$ & $\mathrm{O}$ & 100 & 8.034 & 6.2 \\
$\mathrm{C}_{8} \mathrm{O}_{8} \mathrm{H}_{8}$ & $\mathrm{OH}$ & 100 & 5.505 & 4.32 \\
$\mathrm{C}_{40} \mathrm{O}_{6} \mathrm{H}_{4}$ & $2: 1$ & 20 & 5.123 & 1.135 \\
$\mathrm{C}_{24} \mathrm{O}_{4} \mathrm{H}_{4}$ & $2: 1$ & 33 & 5.295 & 1.518 \\
$\mathrm{C}_{20} \mathrm{O}_{4} \mathrm{H}_{4}$ & $2: 1$ & 40 & 5.76 & 2.398 \\
$\mathrm{C}_{16} \mathrm{O}_{4} \mathrm{H}_{4}$ & $2: 1$ & 50 & 5.785 & 2.698 \\
$\mathrm{C}_{12} \mathrm{O}_{4} \mathrm{H}_{4}$ & $2: 1$ & 67 & 5.465 & 4.13 \\
$\mathrm{C}_{48} \mathrm{O}_{8} \mathrm{H}_{4}$ & $1: 1$ & 25 & 5.511 & 1.568 \\
$\mathrm{C}_{36} \mathrm{O}_{8} \mathrm{H}_{4}$ & $1: 1$ & 33 & 5.765 & 1.865 \\
$\mathrm{C}_{24} \mathrm{O}_{8} \mathrm{H}_{4}$ & $1: 1$ & 50 & 6.489 & 2.545 \\
$\mathrm{C}_{24} \mathrm{O}_{12} \mathrm{H}_{6}$ & $1: 1$ & 67 & 6.781 & 2.609 \\
\hline
\end{tabular}

(refer to Table 1), which indicates that the functionalised $\mathrm{GO}$ is a better option than pristine graphene for hydrogen production. As mentioned before, the dissociation of water forming hydrogen and oxygen is only thermodynamically feasible provided that the CBM of the photocatalyst is more negative than the reduction potential and the VBM is more positive than the oxidation potential; otherwise, it requires the presence of sacrificial reagents. By comparing the energy difference of the GO samples, $\mathrm{GO}$ with $\mathrm{OH} / \mathrm{O}=1: 1$ and 2:1 shows that they are indeed a suitable photocatalyst for overall water splitting with desirable band position especially with $\mathrm{C}_{16} \mathrm{O}_{6} \mathrm{H}_{4}$ estimated to be a highly efficient photocatalyst for visible light. After irradiation, an upward shift of VBM was observed; however, CBM remained constant, causing no oxygen evolution. A set of graphene oxide with 
$44 \% \mathrm{C}-\mathrm{C}, 43 \% \mathrm{C}-\mathrm{O}$ and $13 \% \mathrm{C}=\mathrm{O}$ bonding composition was found to be in the range; however, the performance was still inadequate [89]. This shows that GO is chemically and thermally stable; however, the economic factors favour water dispersibility.

In conclusion, available band gap energy after appropriate reduction is demonstrated to become a promising candidate for hydrogen evolution as a photocatalyst in future. However, developing a facile and precise method to synthesise and reduce the graphene oxide to optimise the performance of photocatalysis whilst achieving desirable band position in practical usage still poses to be a challenge due to limited understanding of the mechanism and theoretical calculations.

\subsection{Wide band gap photocatalyst}

Titanium dioxide $\left(\mathrm{TiO}_{2}\right)$ is the most extensively studied photocatalyst when it comes to water splitting ever since it was first reported back in 1972 and demonstrated by Fujishima and Honda using a photoelectrochemical cell for the decomposition of water [93]. What makes $\mathrm{TiO}_{2}$ so popular as a potential photocatalytic material in water splitting is the unique and favourable properties it holds, such as abundance in nature, economic prospect, nontoxicity and high chemical stability. However, it also suffers from various disadvantages such as the wide band gap limits and rapid recombination of photogenerated electron and holes as well as a backward reaction [80]. Due to these shortcomings, $\mathrm{TiO}_{2}$ nanostructure is usually coupled with carbon materials to help influence the conversion efficiency and have reported having shown much success in improving the photocatalytic activity [94]. Graphitic carbon nitride that demonstrates high stability and moderate band gap has also become attractive in photocatalysis [95]. It was found that the addition of noble metals such as Pt provides better results. However, due to its high cost, alternative co-catalysts are ventured for a possible sustainable solution.

The preparation of $\mathrm{TiO}_{2} / \mathrm{GO}$ composite was explained by Zhang et al. [96]. GO obtained from Hummers' method was dispersed in ethanol solution and sonicated for $1 \mathrm{~h}$, followed by mixing with $\mathrm{TiO}_{2}$ for $1 \mathrm{~h}$. The resulting suspension was maintained at $120{ }^{\circ} \mathrm{C}$ for $3 \mathrm{~h}$ in the autoclave to reduce GO and deposit $\mathrm{TiO}_{2}$. After filtration, rinsing and drying, the $\mathrm{TiO}_{2} / \mathrm{GO}$ composite was obtained from a one-step hydrothermal reaction with considerable reproducibility. A significant improvement in the photocatalytic activity under both UV and visible light was observed and can be explained through the mechanisms that are undergone. Firstly, with the increase in GO composition, the BET surface area, as well as the adsorptivity, is enhanced. Secondly, the band-gap energy of bare $\mathrm{TiO}_{2}$ only corresponds to the wavelength in the UV region of the solar spectrum that only contributes to a small amount of energy, producing photoinduced electron-hole pairs and driving the water splitting. At the same time, the introduction of $\mathrm{Ti}-\mathrm{O}-\mathrm{C}$ bonding extends and broadens the light absorption range to the visible light region (refer to Fig. 8). Also, the existence of $\mathrm{TiO}_{2} / \mathrm{GO}$ forms $\mathrm{p}-\mathrm{n}$ heterojunction as well as an inner electric field at the interface. The graphene accepts excited electrons of $\mathrm{TiO}_{2}$ from the conduction band via percolation mechanism. It inhibits the recombination between electrons and holes effectively, which provokes the separation of excitons as an electron sink $[96,97]$. From the experiment, the optimal GO composition was estimated to be around $2 \%$. The reason for such a low concentration of GO used in the $\mathrm{TiO}_{2} / \mathrm{GO}$ composite may have been due to the collisions of electrons and holes caused by excessive GO content [98].

Other metal oxides such as $\mathrm{ZnO}$ and $\mathrm{Fe}_{3} \mathrm{O}_{4}[99,100]$ are considered as an alternative for $\mathrm{TiO}_{2}$ due to their wide band gap. The effect of graphene incorporation is also noticed and has been tested. Khan et al. [101] produced $\mathrm{ZnO}$ nanowire arrays/rGO (ZnO NWAs/GO) hybrid catalyst and coated it with fluorine-doped tin oxide and observed a tenfold increase in current density at the electrolyte by contrast with pristine $\mathrm{ZnO}$, which is relatively progressive even compared to other novel $\mathrm{ZnO}$-containing hybrid materials such as the core-shell $\mathrm{Fe}_{3} \mathrm{O}_{4}-\mathrm{ZnO} / \mathrm{GO}$ [102], confirming the benefit of GO intercalation. These works can demonstrate the wide availability in the applications of GO in water splitting materials with a wide band gap.

Apart from the graphene oxide content, other factors also need to be optimised. For example, the hydrothermal synthesis is proposed to better accept and transport electrons and benefit from different morphologies such as core-shell which is also considered to enlarge contact area. The electrical conductivity retarded by defects of graphene oxide also

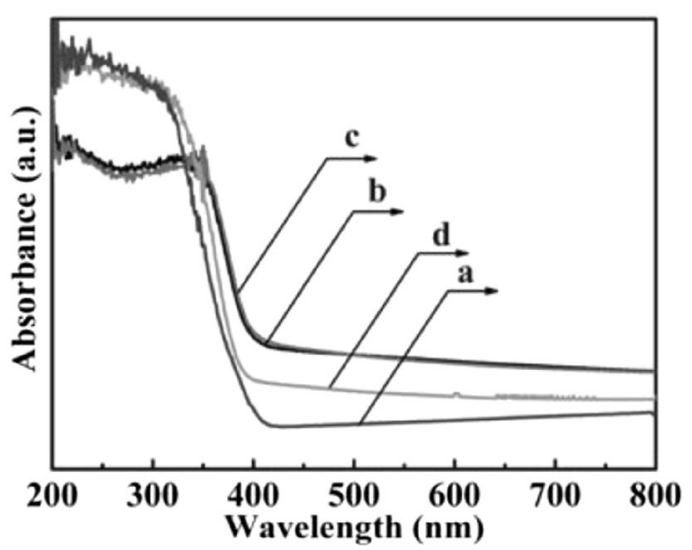

Fig. 8 UV-Vis diffuse reflectance spectra of P25 and the prepared samples, P25 (a), $\mathrm{TiO}_{2} / 1 \mathrm{wt} \% \mathrm{GSs}(\mathbf{b}), \mathrm{TiO}_{2} / 5 \mathrm{wt} \% \mathrm{GSs}(\mathbf{c})$ and $\mathrm{TiO}_{2} / 10 \mathrm{wt} \%$ GSs (d) [97] 
plays a crucial role, therefore requiring the development of a cheap and scalable method for high-quality graphene.

\subsection{Visible-light-absorbing photocatalyst}

$\mathrm{CdS}$ is an attractive photocatalytic material for hydrogen generation when it comes to utilising solar energy as much as possible under visible-light irradiation. This is essential since UV light only occupies approximately $4 \%$ of energy in the solar radiation. However, there prove to be certain limitations due to the aggregation of $\mathrm{CdS}$ particles, eventually leading to a decrease in surface area and an increase in the possibility of recombination of electron-hole pairs [103].

$\mathrm{CdS} / \mathrm{GO}$ was prepared by solvothermal method, the dispersion of $\mathrm{GO}$ and $\mathrm{Cd}(\mathrm{Ac})_{2}$ in dimethyl sulfoxide (DMSO) with sonication was held in the Teflon-lined autoclave at $180^{\circ} \mathrm{C}$ for $12 \mathrm{~h}$ followed by rinsing of acetone and ethanol and finally, drying. The optimal 1\% GO content contributed to a nearly fivefold increase in photocatalytic activity with $22.5 \%$ of quantum efficiency (real number of radicals per photon absorbed/theoretical number of radicals per photon absorbed) in this work, providing more active sites and suppressing the recombination of particles. However, more content of GO will lead to an adverse impact on the performance similar to $\mathrm{TiO}_{2} / \mathrm{GO}$ since the absorptivity of $\mathrm{CdS}$ is weakened by the shield of GO formed on the composite [103].

In terms of water reduction material, $\mathrm{BiVO}_{4}$ as a semiconductor with narrow band gap energy of $2.4-2.6 \mathrm{eV}$ can also absorb visible light intrinsically. It is simultaneously inexpensive, chemically stable, readily available, environmentally friendly yet simple to synthesise [100]. The reason why $\mathrm{BiVO}_{4}$ on its own cannot be utilised as a photo-catalyst is that the relatively low conduction band edge of $\mathrm{BiVO}_{4}$ does not catalyse hydrogen evolution. However, the valence band maximum (VBM) can carry out oxygen formation and is therefore only useful for oxygen evolution once $\mathrm{GO}$ undergoes photocatalytic reduction via $\mathrm{BiVO}_{4}$ to form $\mathrm{BiVO}_{4} / \mathrm{GO}$. The feasibility of $\mathrm{BiVO}_{4} / \mathrm{GO}$ was evaluated, showing considerable evolution of hydrogen and oxygen in the system of $\mathrm{BiVO}_{4} / \mathrm{GO}$ coated with FTO and connected to the Pt counter electrode. The GO is assigned to bring prompt collection and transport of charge since the excellent conductivity of GO facilitates the shuttling of excited electrons between the electrodes. The effect of GO on electrons transport can be concluded by the observation showing a significantly increasing incident photon-to-current conversion efficiency (IPCE) and $\mathrm{BiVO}_{4} / \mathrm{GO}$ having a higher current density than pure $\mathrm{BiVO}_{4}$ under visible light and pure $\mathrm{TiO}_{2}$ under UV irradiation. However, attempts to scale up have always been hindered due to the complexity of the system, expenditure on the counter electrode and limiting the surface area of photoelectrodes exposed [104].
Whilst $\mathrm{BiVO}_{4} / \mathrm{GO}$ is responsible for the oxygen evolution, according to a study carried out by Iwase et al. [105], $\mathrm{Ru} / \mathrm{SrTiO}_{3}: \mathrm{Rh}$ is selected to be the hydrogen photocatalyst. GO was adopted as an electron transport mediator in solid state and applied in the powdered Z-scheme ternary system. The key factors of the degree of GO reduction related to both conductivity and hydrophobicity are emphasised in this study. Since high hydrophobicity resulted from hydrazine reduction of GO, the photocatalytic reduction based on $\mathrm{Ru} / \mathrm{SrTiO}_{3}: \mathrm{Rh}$ instead of $\mathrm{BiVO}_{4}$ can retard the physically inter-particulate interaction between photocatalysts. At $\mathrm{pH}$ condition of 3.5, both $\mathrm{BiVO}_{4}$ and $\mathrm{Ru} / \mathrm{SrTiO}_{3}: \mathrm{Rh}$ are attracted to aggregate with $\mathrm{GO}$, and this electron mediator provides electrons for the pathway from the conduction band of $\mathrm{BiVO}_{4}$ to $\mathrm{Ru} / \mathrm{SrTiO}_{3}: \mathrm{Rh}$. However, the recombination is hindered, as the migration of electrons in $\mathrm{BiVO}_{4}$ and holes in $\mathrm{Ru} / \mathrm{SrTiO}_{3}: \mathrm{Rh}$ to reactants (water) is extremely accessible.

Finally, graphene with tuneable and high work function mentioned in 2.1 is confirmed to replace typical co-catalyst, noble metal. Besides functioning as an acceptor and transporter of electrons mentioned in both wide band gap and visible-light-absorbing photocatalysts, the effect of graphene as a co-catalyst is usually ignored. Although the hydrogen production rate is enhanced in every case, the inherently synergetic interaction between semiconductor and graphene, other co-catalyst and graphene, is still unclear. To indirectly acquire the information of photoinduced charge transfer and understand the molecular-level mechanism, a theoretical calculation is required.

\section{Water treatment}

Owing to the rapid industrialisation and growing population, the introduction of various species of contaminants into the water systems has become a significant issue, causing the global community to be in urgent need of environmental technologies for water treatment. Generally, surfactants are widely applied in various fields to remove the contaminants in the industries such as paper, polymer, pharmaceuticals and oil products. There are more specific examples of contaminants that are prone to finding their way into water systems. For instance, dodecylbenzenesulfonate (DBS), one of the alkyl-benzenesulfonates produced as surfactant groups, is commonly drained into the water system [106]. Polycyclic aromatic hydrocarbons (PAHs) are usually formed by combustion of petroleum and biomass [107]. A certain part of pharmaceutical waste and drug uptake such as dipyrone (DIPY) remains unchanged in the human body before eventually being transported out into the water system via urinary excretion and then hydrolysed into harmful 4-methylaminoantipyrine (4-MAA) [108]. Even dyes and pigments that are widely used in industrial manufacture and household are left 
for us to address [106]. The substances that were just mentioned, like many other substances that find their way into water systems, are non-biodegradable and can accumulate in the water ecosystem over a long period, disrupting the aquatic life and endangering human health via food chain $[107,109]$. Currently, there are various existing strategies, such as advanced oxidation technologies (AOTs) and photocatalysis that have been explored for the treatment of water systems. However, more effective remediation of these strategies is required.

\section{1 $\mathrm{TiO}_{2}$ photocatalysis}

It has been the focus of many research teams to discover novel composite materials that can degrade organic pollutants efficiently by generating oxidising radicals that react with contaminants to produce water and $\mathrm{CO}_{2}$. Due to graphene's high performance in photocatalysis as a co-catalyst, $\mathrm{TiO}_{2} / \mathrm{GO}$ with outstanding photocatalytic performance mentioned above came into sight. The photocatalytic activity was evaluated by measuring the degradation of basic dyes such as rhodamine $\mathrm{B}(\mathrm{RhB})$ or methylene blue $(\mathrm{MB})$ over the UV-Vis spectra. When using $\mathrm{TiO}_{2} / \mathrm{GO}$ photocatalyst, significant decomposition was observed. Up to $88 \%$ of MB was removed after less than 100 min under UV irradiation, whilst $52 \%$ of MB was removed under visible light. In comparison, when using pure graphene, pure $\mathrm{TiO}_{2}$ and physically mixed $\mathrm{TiO}_{2} / \mathrm{GO}, 60-70 \% \mathrm{MB}$ was left when under UV irradiation, whilst $87 \%$ was still present when irradiated under visible light [110]. In another experiment carried out by Selim Arif Sher Shah et al. [98], photocatalytic activity was tested by the degradation of $\mathrm{RhB}$ and a similar conclusion with $98.8 \%$ of removal after $80 \mathrm{~min}$ was demonstrated. The mechanism demonstrates that this increase in photocatalytic activity is due to electrons trapped in the electron sink. These trapped electrons cause GO and the excited electrons on the surface of $\mathrm{TiO}_{2}$ to be shuttled throughout the conducting network and react with dissolved oxygen and water, forming the hydroxyl radical to degrade the dye [98, 110]. Hence, rapid charge separation hinders the recombination, both increasing the activity and the ability of adsorption because of more available active sites on the surface. Except for the oxygen absorbed on the surface of graphene, the pi-pi conjugation with aromatic regions in graphene leads to the transfer of dye molecules from solution to the surface, which increases the adsorptivity of organic molecules.

Neppolian et al. [106] synthesised a Pt-GO-TiO 2 composite catalyst for the degradation of DBS. The method for synthesising it was similar to that of $\mathrm{TiO}_{2} / \mathrm{GO}$, which was through an ultrasonic-assisted hydrothermal method. This was then followed by mixing the composite with $\mathrm{H}_{2} \mathrm{PtCl}_{6}$ and irradiating under UV light and inert atmosphere for $3 \mathrm{~h}$. Finally, after washing with water and drying, the required composite catalyst was obtained. Upon evaluation, it was found that GO does not contribute considerably to the degradation of DBS, as it only increased the removal by $15 \%$ after one hour at a $\mathrm{pH}$ of 5 . However, with the doping of $\mathrm{Pt}$, both \% degradation and mineralisation of DBS exhibit a significant increase of $20-30 \%$ in mineralisation compared to $\mathrm{TiO}_{2} / \mathrm{CNTs}$. Also, according to XPS analysis, the interaction of Pt-GO-TiO ${ }_{2}$ leads to the reduction of more $\mathrm{GO}$ from 43 to $68 \%$. This proves that the improved graphite nature of GO provokes the transfer of photoexcited electrons further. Adsorption of DBS was also observed to be increased from $5 \%\left(\mathrm{TiO}_{2}\right)$ and $10 \%\left(\mathrm{GO}-\mathrm{TiO}_{2}\right)$ to $35 \%\left(\mathrm{Pt}-\mathrm{GO}-\mathrm{TiO}_{2}\right)$ at an optimal pH of 5 and 7 [106].

In another study, Yang et al. [111] decorated $\mathrm{TiO}_{2} / \mathrm{GO}$ composite with $\mathrm{Ag}_{3} \mathrm{PO}_{4}$ to strengthen the bactericidal effect. The GO dispersion was mixed with $\mathrm{AgNO}_{3}$ solution and $\mathrm{P} 25$ aqueous dispersion, followed by $\mathrm{Na}_{2} \mathrm{HPO}_{4}$ solution. After centrifugation, washing and drying at $60{ }^{\circ} \mathrm{C}$ in a vacuum, $\mathrm{TiO}_{2} / \mathrm{Ag}_{3} \mathrm{PO}_{4} / \mathrm{GO}$ was synthesised. However, it is noteworthy that the molar ratio of $\mathrm{Ag}_{3} \mathrm{PO}_{4} / \mathrm{TiO}_{2}$ is crucial to the bactericidal performance, and the optimal ratio is suggested as 0.6. The pure $\mathrm{Ag}_{3} \mathrm{PO}_{4}$ is susceptible under light irradiation, which leads to reduction from $\mathrm{Ag}^{+}$to metallic $\mathrm{Ag}$, but with the rapid charge transfer provided by $\mathrm{TiO}_{2} / \mathrm{GO}$, it can be effectively prevented. The synergistic effect also brings about the transformation from GO to rGO, and sufficient reactive oxygen species mainly consist of superoxide radicals that act on both dye molecules and bacteria. Thus, more photogenerated holes are produced in the valence band of $\mathrm{Ag}_{3} \mathrm{PO}_{4}$ and transferred to the $\mathrm{TiO}_{2}$, directly oxidising contaminants and suppressing the recombination. Hence, $\mathrm{TiO}_{2} /$ $\mathrm{Ag}_{3} \mathrm{PO}_{4} / \mathrm{GO}$ composite exhibits an excellent bactericidal effect on various typical pathogenic bacteria accompanied with stability, which is reflected in a significant and rapid decrease from 6-6.5 to 3-4 Log colony-forming units $/ \mathrm{mL}$ after only $1 \mathrm{~h}$ of incubation [111].

\subsection{Photo-Fenton reaction}

Besides the pathway forming radicals in $\mathrm{TiO}_{2}$ photocatalysis, $\mathrm{Fe}^{3+}$ can also be reduced to $\mathrm{Fe}^{2+}$ by $\mathrm{H}_{2} \mathrm{O}_{2}$ or electrons directly, and $\mathrm{Fe}^{2+}$ reacts with $\mathrm{H}_{2} \mathrm{O}_{2}$ continuously, producing hydroxy radicals and converting back to $\mathrm{Fe}^{3+}$. The presence of GO can accelerate the redox cycle of $\mathrm{Fe}^{3+} / \mathrm{Fe}^{2+}$ because of the promotion in the electrons transfer from the conduction band of $\mathrm{Fe}_{2} \mathrm{O}_{3}$ to surface $\mathrm{Fe}^{3+}$ of the catalyst. This is reflected by the fact that the rate constant of $\mathrm{GO}-\mathrm{Fe}_{2} \mathrm{O}_{3}$ (optimal 5\%:1) was observed to be fourfold higher than that of pure $\mathrm{Fe}_{2} \mathrm{O}_{3}$ [112].

The biodegradability of $\mathrm{TiO}_{2}$ photocatalysis was confirmed to be generally less than that of the photo-Fenton process [108]. The existing challenges for the photo-Fenton process are commonly attributed to the narrow working $\mathrm{pH}$ 
range (2-3) that prevents hydrolysis of ferrous and ferric ion, causing difficulty in removing iron-containing sludge [113, 114]. In efforts to resolve this problem, Guo et al. [113] added $\mathrm{Fe}\left(\mathrm{NO}_{3}\right)_{3}$ to $\mathrm{GO}$ dispersion and reacted it for $2 \mathrm{~h}$ at $60{ }^{\circ} \mathrm{C}$. He then centrifuged and washed the mixture with distilled water and dried it at ambient temperature, synthesising the $\mathrm{GO}-\mathrm{Fe}_{2} \mathrm{O}_{3}$ hybrid. The results showed that the hybrid broadened the $\mathrm{pH}$ range from 2.09 to 10.09 , and even at $\mathrm{pH} 10.09$, the degradation of $\mathrm{RhB}$ was up to $90.9 \%$ after $80 \mathrm{~min}$. It was also shown that $\mathrm{GO}-\mathrm{Fe}_{2} \mathrm{O}_{3}$ hybrid catalyst displays some other useful properties that make it stand out as an economically and environmentally sustainable catalyst, such as separability from solution by facile precipitation and its high reusability. The investigation exhibited that even after 10 reuse cycles, the decolourisation of MB remained at $99 \%$, and no iron leaching was detected through ICP-OES [114].The main contributing factor to the biodegradability of the photo-Fenton process is the additional hydroxy radicals and the collapse of iron complexes under UV irradiation [108]. Similar to the mechanism mentioned above, superoxide radicals and hydroxyl radicals that are mainly produced by heterogeneous reactions on the surface rather than by homogeneous catalysis of leached iron in the solution [113] are responsible for the degradation.

Other iron oxides such as $\mathrm{Fe}, \mathrm{Fe}_{3} \mathrm{O}_{4}$ and $\mathrm{FeOOH}$ incorporated with graphene have also been successfully synthesised and applied in the photo-Fenton reaction [115-117], and researches towards functional species into those catalysts have been conducted to delicately tailor the GO-iron oxide composite to meet the prime target of water treatment. For instance, the polyacrylamide (PAM) was introduced, and it formed $\mathrm{Fe}_{3} \mathrm{O}_{4} / \mathrm{GO} / \mathrm{PAM}$ hydrogels that could simultaneously adsorb heavy metal ions [118]. The three-dimensional graphene aerogel also drew attention. Liu et al. [117] inserted CNTs to enhance the FeOOH nanorods supported on GO aerogel, which can avoid restacking of graphene layers and bring porosity. GO-CNT dispersion was prepared by ultrasonication and mixed with $\mathrm{FeSO}_{4} \cdot 7 \mathrm{H}_{2} \mathrm{O}$. Then, the mixture was hydrolysed at $95^{\circ} \mathrm{C}$ for $6 \mathrm{~h}$ and then lyophilised, obtaining the $\mathrm{FeOOH}$ nanorods anchored on GO-CNTs aerogel matrix catalyst ( $\mathrm{FeOOH} / \mathrm{GCA})$ from a metal-ion-induced self-assembly process. The $\mathrm{FeOOH} / \mathrm{GCA}$ exhibits excellent durability after six cycles and significant degradation towards various organics such as dye including $\mathrm{RhB}$ and $\mathrm{MB}$, phenol and BPA, which is partially attributed to abundant active sites provided by the $3 \mathrm{D}$ and porous structure. The drawbacks of photo-Fenton reaction are the higher cost compared to $\mathrm{TiO}_{2}$ photocatalysis [119], but both removal and mineralisation of organics are still better in photo-Fenton reaction. Subsequent recovery of $\mathrm{pH}$ is still required since acidic intermediates form continuously though the decrease in $\mathrm{pH}$ with time is welcomed by degradation. Meanwhile, the dosage of $\mathrm{H}_{2} \mathrm{O}_{2}$ also needs to be controlled at a level that can degrade efficiently but avoid scavenging hydroxyl radicals to form water.

\subsection{Sulphate-based AOP}

Bisphenol A (BPA), also known as its chemical name 2,2-(4,4-dihydroxy phenyl) propane, is an estrogen-like endocrine-disrupting chemical (EEDC) which has two unsaturated phenol rings and is used in the manufacturing of polycarbonate plastics and epoxy resin which includes food packaging, lacquers for can coating, bottle tops and dentistry [120-122]. BPA is known to bind with both ER $\alpha$ and ER $\beta$ and plays either estrogenic or anti-estrogenic roles in vitro $[120,123,124]$, interacting with the endocrine system leading to adverse health effects in humans and aquatic species even at low concentrations $[123,125]$. The low dosage of BPA can give rise to hypertension, heart diseases, diabetes, prostate cancer, genital malformation and others [124, 126], making it necessary to remove BPA from water sources. Unfortunately, traditional water treatment is not effective for treating EEDC; hence an advanced oxidation process based on sulphate radical $\left(\mathrm{SO}_{4}^{-{ }^{-}}\right)$has been recently explored and found to possess higher oxidative potential at $2.5-3.1 \mathrm{~V}$ compared to hydroxyl radicals at $2.7 \mathrm{~V}$ [127], gaining lots of interest in wastewater treatment. Peroxymonosulfate (PMS) is a well-known precursor in generating powerful oxidising $\mathrm{SO}_{4}^{-}$which can attack oxidisable agents and degrade organic contaminants [128]. Despite the promising properties PMS holds in handling organics, it remains stable in aqueous solution, showing low reactivity towards pollutants [129]. Hence, appropriate PMS activation is needed to generate radicals.

Du et al. [129] proposed that $\mathrm{Fe}_{3} \mathrm{O}_{4}$ could provide better dispersion distribution rate as magnetic support to assist in the separation phase and to immobilise the composites onto GO. In their experiment, $\mathrm{Mn}-\mathrm{MGO}$ was synthesised by supporting $\mathrm{MnO}$ onto magnetic $\mathrm{Fe}_{3} \mathrm{O}_{4} / \mathrm{GO}(\mathrm{MGO}$ ), and the catalytic performance was evaluated during the oxidation of BPA with PMS. First, $\mathrm{MnO}$ was synthesised via reduction of $\mathrm{KMnO}_{4}$ by ethylene glycol, followed by hydrothermal treatment right after. The synthesised hybrid particles were then separated using a magnet and washed with ultrapure water before drying in a vacuum oven overnight. The experiment was carried out in a vessel containing a reaction solution with BPA and PMS concentrations being known. From the results, it was observed that Mn-MGO/PMS couple demonstrated very high reactivity with more than $95 \%$ of the BPA being converted, suggesting that $\mathrm{Mn}$ species were necessary for PMS activation for sulphate radicals' generation. The hybrid showed good dispersibility and magnetic recyclability, exhibiting considerably good performance even after five recycling runs. The result was compared, with different reaction systems. As expected, Mn-MGO/PMS 
significantly reduced the amount of BPA in the solution, which indicates that the degradation results from the synergic effect of Mn-MGO/PMS couple (refer to Fig. 9). For the degradation pathway of BPA, the generated $\mathrm{SO}_{4}{ }^{-}$will first attack the BPA and capture one electron from the aromatic ring forming phenolic radicals. The BPA radicals were then decomposed into phenol and $p$-isopropenyl phenol where further oxidation gave rise to the transformation of benzoquinone and hydroxybenzoic acid. Under acidic conditions, water molecules could attack the phenolic radicals forming

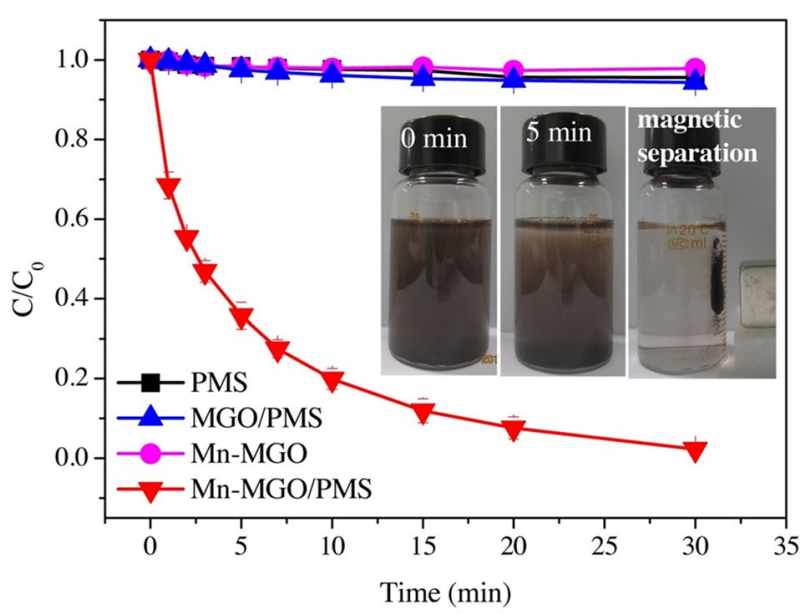

Fig. 9 BPA degradation in different reaction systems [129] hydroxylation of the aromatic rings. After that, it underwent dehydration forming quinone and carboxylic compounds. Finally, the aromatic compounds were converted to ringopened intermediate, which could be mineralised [129] (refer to Fig. 10). Mn-MGO catalyst demonstrated high efficiency in PMS activation with long-term stability and shed light on the possible alternative method for $\mathrm{SO}_{4}{ }^{-}$-based oxidation of organic pollutants.

Reduced graphene oxide acting as a metal-free catalyst for the activation of PMS was evaluated by Sun et al. [127] by comparing a series of nanocarbons and the typical cobalt catalyst $\mathrm{Co}_{3} \mathrm{O}_{4}$ that has been used in the oxidation of organic contaminants. From the observation, there was a significant difference in the amount of phenol removed between GO and rGO, implying that the determining factor is the number of active sites of graphene that are considered to be the zigzag edges. The high chemical activity is explained by the mobility of pi electrons at zigzag edges, enabling the electrons to be transported to PMS which forms $\mathrm{SO}_{4}{ }^{-}$and $\mathrm{SO}_{5}{ }^{--}$that degrade the phenol. Apart from acting as a non-metal catalyst for the degradation of phenol, rGO is also regarded as a promising route to later $\mathrm{Co}_{3} \mathrm{O}_{4}$ for the activation of PMS to degrade dichlorophenol and dye molecules such as $\mathrm{MB}$.

$\mathrm{Mn}_{3} \mathrm{O}_{4}-\mathrm{rGO} / \mathrm{PMS}$ system, a $\mathrm{Mn}_{3} \mathrm{O}_{4}-\mathrm{rGO}$ hybrid with the presence of PMS, was found to exhibit competing catalytic activity towards dye molecules as photo-Fenton reaction, and $\mathrm{TiO}_{2}$ photocatalysis mentioned previously [130] as well as displaying the highest catalytic activity (refer to Fig. 11).

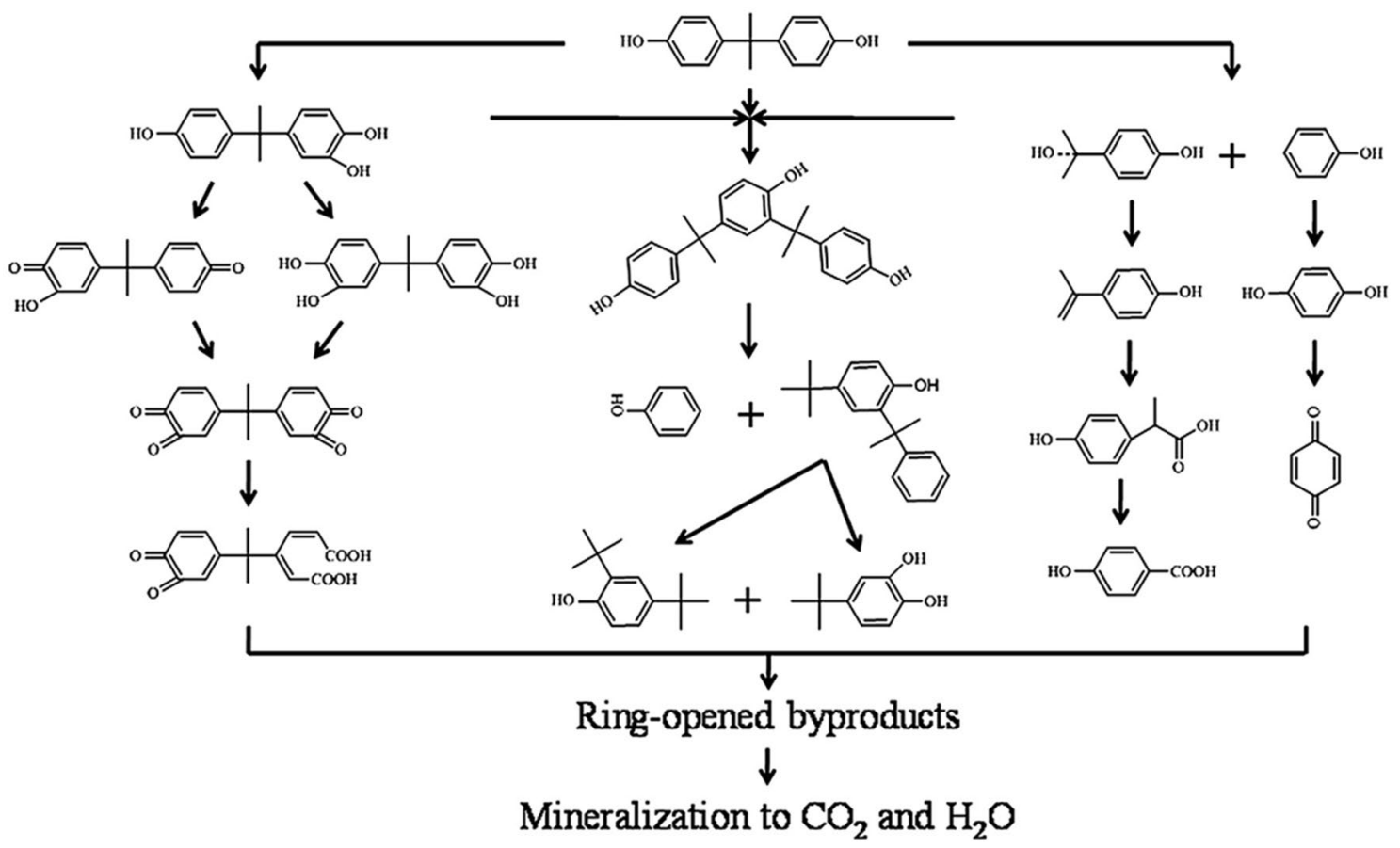

Fig. 10 Possible degradation pathways of BPA in the Mn-MGO/PMS system [129] 


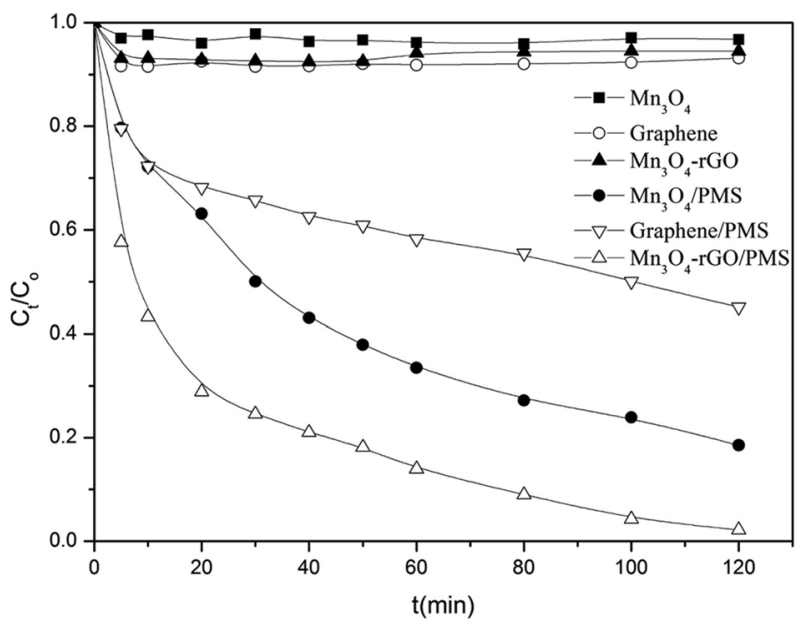

Fig. 11 Orange II concentration at different conditions [130]

The degradation of Orange II was tested, and it was observed that the colour gradually diminished with the presence of the hybrid catalyst, indicating that the chromophoric structure of Orange II was destroyed. It also demonstrated good recyclability as well after four cycles, and XRD measurements showed the structure of catalyst with close to no change before and after the reaction, indicating long-term stability. It stated that the triple-bond $\mathrm{Mn}^{2+}$ species react with PMS to generate $\mathrm{SO}_{4}{ }^{-}$and the superb catalytic activity of the hybrid is due to the positive synergistic effects between $\mathrm{Mn}_{3} \mathrm{O}_{4}$ and grapheme [131]. Through the oxygen groups, the manganese atoms are covalently bonded to the graphene sheets, and rGO contains defects ideal for oxidation and reactive adsorption. The hybrid also has a high surface area, thereby providing more active sites. The long-term stability is due to the nature of graphene to prevent aggregation of $\mathrm{Mn}_{3} \mathrm{O}_{4}$ nanoparticles, preventing a loss of surface area. In short, the hybrid catalyst has a potential in the advancement of a catalyst with high catalytic activity in water treatment owing to its low cost and simple preparation. Compared with hydroxyl radicals in $\mathrm{TiO}_{2}$ photocatalysis and photo-Fenton reaction, the sulphate radicals are more reactive since longer life span allows them to be more likely to collide with organics. As a metal-free catalyst, graphene is not only superior to other carbons but also outperforms popular transition metal oxides, and when coupled with metal oxide catalysts, both efficiency and reusability are promoted.

\section{Fischer-Tropsch synthesis (FTS)}

Discovered in Germany [132] by Franz Fischer and Hans Tropsch in the 1920s [133, 134], FTS is a highly exothermic reaction which converts synthesis gas into liquid fuels (refer to Eq. (6)) [132, 135]. Synthesis gas can be obtained from sources such as natural gas, biomass or coal, and it is generally a mixture consisting of carbon monoxide and hydrogen [134].The transformation process of carbon source to FTS product is named after the type of feedstock, for instance gas-to-liquid (GTL), coal-to-liquid (CTL) and biomass-toliquid (BTL) [135, 136]. Before Fischer-Tropsch synthesis can take place, the carbon source has to be converted to synthesis gas via partial oxidation, steam reforming or gasification processes [136]. The products of FTS are water and the hydrocarbons that mainly consist of n-paraffin and $\alpha$-olefin [134].

FTS: $\quad \mathrm{CO}+2 \mathrm{H}_{2} \rightarrow-\mathrm{CH}_{2}-+\mathrm{H}_{2} \mathrm{O} \quad-165 \mathrm{~kJ} \mathrm{~mol}^{-1}$

The growing demand for transportation fuels has called for a promising technology in solving the shortage of liquid transport fuel [137]. FTS which is a method for synthesising clean fuel using resources that are abundant on Earth [125, $126]$ is experiencing remarkable development and research [120] as it gives a promising technology in solving the shortage of liquid transport fuel [137]. Another important potential substitute for fossil fuel is biomass, mainly due to it being both natural and renewable [138, 139]. Biomass has been widely explored on its conversion to liquid transportation fuels (BTL) to encourage environmental preservation.

$\mathrm{Co}$ and $\mathrm{Fe}$ are commercially used as catalysts in FTS [134], but $\mathrm{Ru}$ is the most efficient one as it can catalyse the reaction as a pure metal itself without the presence of a promoter, accelerating a simple catalytic process [140, 141]. However, the high cost of Ru has impeded its usage for industrial application. In terms of pros and cons, $\mathrm{Fe}$ is relatively cheaper than Co and relatively active at more severe conditions, but Co is less likely to undergo deactivation by water. Meanwhile, $\mathrm{Fe}$ has a wide operating temperature and flexible $\mathrm{H}_{2} / \mathrm{CO}$ ratio, hence a higher water gas shift (WGS) reaction, which is particularly suitable for synthesis gas conversion with low $\mathrm{H}_{2} / \mathrm{CO}$ ratios [141]. A detailed comparison in each field between $\mathrm{Fe}$ and Co catalyst was listed in the review [142].

\subsection{Graphene-based iron catalyst}

In iron catalysts, there is always an interaction between the $\mathrm{Fe}$ and common supports such as alumina and silica leading to the formation of mixed metal oxides which are difficult to reduce effectively, consequently limiting the catalytic activity [143-145]. Due to this, it is necessary to explore support for the catalyst with little interactions with $\mathrm{Fe}$. Recently, there has been growing attention on the use of GO as $\mathrm{Fe}$ carrier due to the large surface area, low cost and the oxygen-containing group which can tune the metal interaction. The presence of extended $\pi$-system and high electron density enables the metal oxide nanoparticles formed to be 
easily reduced on the surface of GO. The defect sites which are presented in stacked layers also act as good anchoring sites for well-dispersed Fe nanoparticles [146] and provide remarkable catalytic properties and stability [145, 147]. According to Zhao et al. [148], the oxygen-containing groups on the surface result like the acidic surface of GO and to increase the conversion of synthesis gas the hightemperature treatment is usually applied to reduce the GO and further enhance the FTS reaction.

$\mathrm{Fe} / \mathrm{GO}$ composites were then synthesised by Wei and co-workers [146] via hydrothermal method followed by a further thermal pre-treatment in argon. $\mathrm{Fe}(\mathrm{NO})_{3}$ was first added into $\mathrm{GO}$ water solution and stirred before being transferred to a Teflon-lined autoclave in an oven at $120^{\circ} \mathrm{C}$. The products were then washed with ethanol upon cooling and dried. After that, the products were pre-treated in argon at different temperatures until finally testing for FTS reaction in a fixed bed reactor. The $\mathrm{CO}$ conversion was identified with the aid of a gas chromatogram by comparing the gas of the reactant and product. The results showed that the $\mathrm{CO}$ conversion after $500{ }^{\circ} \mathrm{C}$ treatment was up to $39 \%$ and the selectivity of C5 + was interestingly $37.7 \%$ which is considerably higher than other graphene-based iron catalysts. With the increase in temperature in the thermal treatment, the reduction of oxygen species and sintering of nanoparticles should decrease the BET surface area. However, it was observed from the experiment that $\mathrm{Fe} / \mathrm{GO}$ samples calcinated at $500{ }^{\circ} \mathrm{C}$ have larger surface area than those at a lower temperature, providing more active sites for synthesis gas adsorption. This is because the breakage of GO sheets structure gives rise to the large voids and channels between the sheets, enabling the inner surfaces to be fully exposed to iron oxide nanoparticles that are easily accessible for hydrogen and carbon monoxide, as well as avoiding more agglomeration of nanoparticles with the decrease in mobility (refer to Fig. 12). This suggests that the calcination lowers the binding energy and weakens the interaction between larger iron oxide nanoparticles and GO, which in turn decreases the temperature of reduction.

Active $\mathrm{Fe}_{5} \mathrm{C}_{2}$ iron carbide phase is observed when graphene is introduced during the FTS, which is considered to explain the relatively lower water-gas shift activity and a significant reduction of undesirable $\mathrm{CO}_{2}$ compared to the CNT-supported one. According to the previous introduction, Fe provides high WGS activity demonstrating good flexibility in processing synthesis gas with a wide range of $\mathrm{H}_{2} / \mathrm{CO}$ ratios. Carbon supports bond weakly to $\mathrm{Fe}$ with large pore volumes further enhancing the catalytic activity and stability [149]. Then, the intercalation of promoter awaits the discovery and exploration. Nasser et al. [150] explored iron catalyst loaded on rGO with different levels of $\mathrm{Mn}$ content for the production of light olefins in FTS. Nasser's report claimed that $\mathrm{Mn}$ doping promoted $\mathrm{Fe}$ nanoparticles catalyst with the formation of Mn-rich layer around Fe-rich core where its outer layer is beneficial for olefin formation, and this can be controlled by adjusting the adsorption ability and surface properties of the catalyst. It also stabilised the active iron phase acting as an electron donor similar to that of alkali promoters [151]. This stabilising effect was believed to increase the olefin and C $5+$ species selectivity and the tunable properties of $\mathrm{Mn}$ shell thickness which are conductive to catalytic performances in FTS.

According to observation, Mn-containing catalyst has been reported to enhance the selectivity of olefin with the increment of dissociative $\mathrm{CO}$ adsorption on catalyst surface, whilst the $\mathrm{H}_{2}$ adsorption is reduced [150, 152]. Lohitharn
Fig. 12 A simple illustration of the effect of argon pre-treatment in the supported catalyst [146]

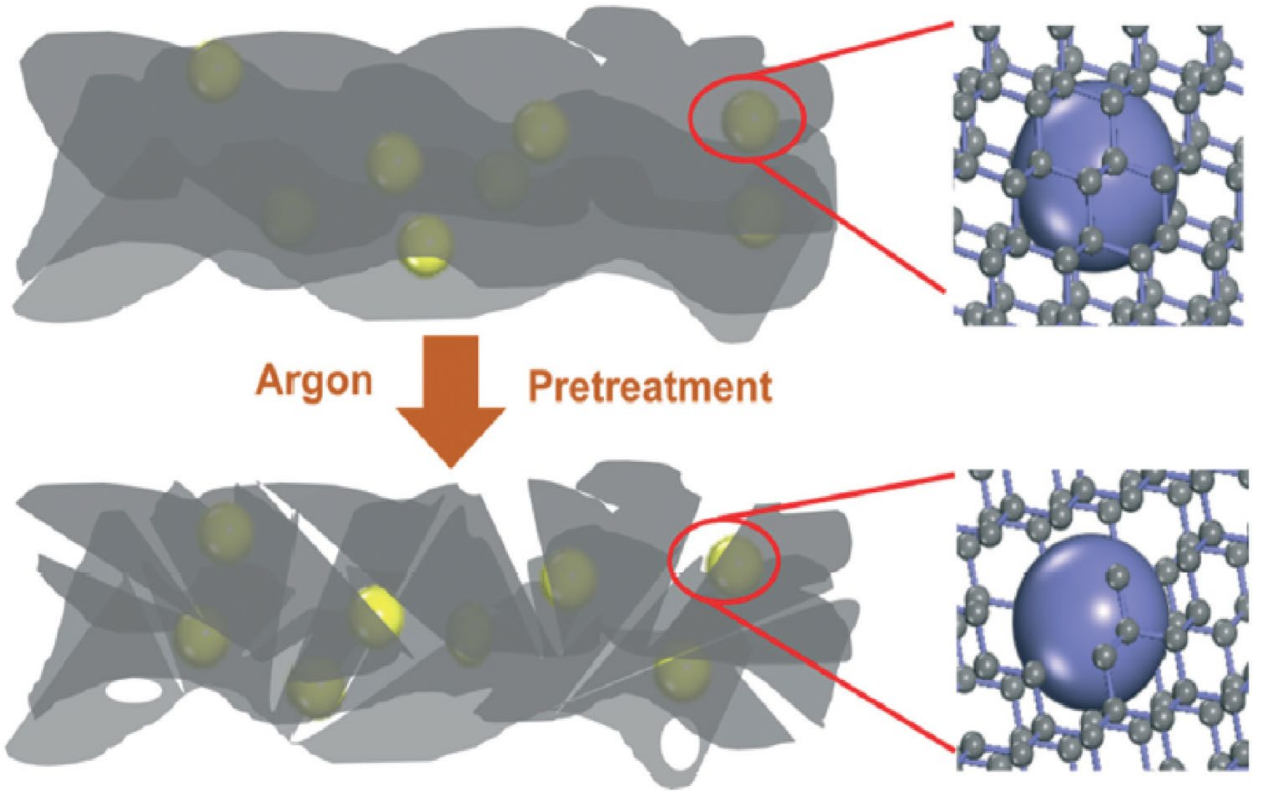


et al. [153] demonstrated that Mn-promoted Fe catalyst causes a higher light olefin formation compared to the unpromoted ones. Meanwhile, rough and defected graphene sheets with large surface area and oxygen-containing groups are preferred as smooth graphene sheets caused nanoparticles to move freely on graphene leading to sintering and segregation $[150,154,155]$. Nanoparticles on graphene sheets also act as a spacer, hindering the stacking of graphitic structures and increasing the surface area of the catalyst composite [155]. The potential of graphene-based iron catalyst in FTS is considerable, but the role of iron carbide phase that contributes to this has rarely been investigated. This transition metal carbides that dissolve interstitially in transition metals' crystal lattice is believed to affect FTS profoundly, and indeed experiments agree with carburised iron as an active catalyst. However, there are still debates and doubts about whether bulk iron carbides themselves are necessary for FTS or whether it is completely attributed to metallic iron, whether the graphene introduced facilitates the formation of iron carbides and then increases the activity. If so, whether the different configurations of iron carbides lead to different levels of promotion in activity and selectivity can only be affirmed once more studies have been carried out on the mechanisms.

\subsection{Graphene-based cobalt catalyst}

One of the advantages of $\mathrm{Fe}$ catalyst is that the selectivity and activity in FTS can be varied widely in the presence of a promotor. However, there are few promotors for Co catalyst to control selectivity. The high water-gas shift described as the merit of $\mathrm{Fe}$ catalyst is not always considered as necessary and desirable. If the composition of synthesis gas is in high $\mathrm{H}_{2} / \mathrm{CO}$ ratio that is from natural gas rather than coal, lower water gas shift is expected. When the degree of $\mathrm{CO}$ conversion rises to a certain extent, the carbon efficiency of Co can be nearly twofold greater than Fe catalyst [142]. The cobalt catalyst is favoured for its high selectivity and activity to linear paraffin as well as high stability. Research related to carbon support for it has been progressed for a long period. However, the activity and selectivity are too dependent on the deposition of cobalt, resulting in nanoparticles on the outside surface suffer from the lower activity and more sintering [156].

The GO was impregnated to $15 \mathrm{wt} \% \mathrm{Co}\left(\mathrm{NO}_{3}\right)_{2} \cdot 6 \mathrm{H}_{2} \mathrm{O}$ aqueous solution followed by drying and calcination at $450{ }^{\circ} \mathrm{C}$ for $3 \mathrm{~h}$ under argon atmosphere. The BET surface area $\left(602 \mathrm{~m}^{2} / \mathrm{g}\right)$, pore volume size and distribution $(1.46$ $\mathrm{cm}^{3} / \mathrm{g}$ ) of Co/GNS obtained from TEM images all outweigh that of the control group, $\mathrm{Co} / \mathrm{CNTs}$ and $\mathrm{Co} / \mathrm{Al}_{2} \mathrm{O}_{3}$. From TPR analysis, the reduction temperature is shifted downwards by graphene, showing a $12 \%$ increase in $\mathrm{CO}$ conversion and a $22 \%$ increase in FTS rate in comparison with $\mathrm{Co} /$
CNTs. Apart from more C5 + product, the most inspiring improvement is on the stability since only $18 \% \mathrm{CO}$ conversion is lost after $480 \mathrm{~h}$ synthesis, before $35 \%$ in Co/CNTs [156, 157].

A similar procedure was conducted to evaluate the nitrogen-doping graphene-based cobalt catalyst (Co/N-GNS). Apart from slightly increasing the FTS rate, the Raman spectroscopy suggested that more defects ascribed to N-doping as nucleation sites hampered the agglomeration of nanoparticles further. Due to the characteristics of the nitrogen functional group, the adsorption of hydrogen is increased, producing more paraffin rather than heavies due to chain growth. This causes the selectivity of $\mathrm{C} 5+$ to be lower than that of $\mathrm{Co} / \mathrm{GNS}$. However, the lower olefin to paraffin ratio also means a lower formation of coke on the surface. The advance is mainly reflected in the catalyst stability, as the loss of activity caused by irreversible deactivation of $\mathrm{Co} / \mathrm{N}$ GNS is only $0.6 \%$ whilst undergoing less agglomeration, sintering and refractory coke formation [158]. To date, limited studies based on the graphene-based FTS catalyst have been conducted, leaving great potential for the development in future. Although the currently available literature favours graphene-based iron in every aspect, there has been no clarification about the mechanisms of incorporating graphene yet. As for the incorporation of other nanoparticles, heteroatoms doping, morphology, etc., the subsequent exploration of them remains far from now.

\section{Conclusion and prospect}

The structure of graphene, along with its outstanding electrochemical properties, has inspired many researchers from various fields of study to explore and develop different derivatives of graphene to improve its properties and applications. One major field of interest and potential is catalysis, due to its outstanding electrochemical properties as well as facile and cheap synthesis methods. This review was focused on four main applications, namely oxygen reduction reaction, water splitting, water treatment and Fischer-Tropsch synthesis. The specific application of graphene materials in each process and their associated preparation and mechanism were discussed in detail. Comparisons with commercial catalysts were drawn and shown to have many advantages over existing catalysts. Nevertheless, the development of graphene is still in its early stage of infancy, and future and further works are needed to optimise graphene-based catalysts. However, this is not without challenges. Firstly, specific techniques for characterisation and theoretical calculations are needed to fully understand the underlying mechanisms where a theoretical and conceptual system can illustrate the role of each tailoring and indicate the potential research direction that is needed. Secondly, the corresponding facile 
synthesis method needs to be developed ensuring that it can adjust the desirable properties precisely and simultaneously.

Acknowledgements The authors gratefully express gratitude to all parties who have contributed towards the success of this project, both financially and technically, especially the S\&T Innovation 2025 Major Special Programme (Grant number 2018B10022) and the Ningbo Natural Science Foundation Programme (Grant number 2018A610069) funded by the Ningbo Science and Technology Bureau, China, as well as the UNNC FoSE Faculty Inspiration Grant, China (PCH2020). The Zhejiang Provincial Department of Science and Technology is also acknowledged for this research under its Provincial Key Laboratory Programme (2020E10018).

\section{Compliance with ethical standards}

Conflict of interest On behalf of all authors, the corresponding author states that there is no conflict of interest.

\section{References}

1. Huang C, Li C, Shi G (2012) Graphene based catalysts. Energy Environ Sci 5(10):8848-8868

2. Zhao $\mathrm{H}$ et al (2015) Screening of metal oxides for $\mathrm{Hg} 0$ capture. Energy Procedia 75:2421-2426

3. Julkapli NM, Bagheri S (2015) Graphene supported heterogeneous catalysts: an overview. Int J Hydrogen Energy 40(2):948-979

4. Su C, Loh KP (2013) Carbocatalysts: graphene oxide and its derivatives. Acc Chem Res 46(10):2275-2285

5. Marras F (2010) Recovery and recycling of homogeneous catalysts: silica as temporary or permanent support, in Faculty of Science (FNWI). University of Amsterdam, p 138

6. Gomes JF et al (2008) Development of heterogeneous catalysts for transesterification of triglycerides. React Kinet Catal Lett 95(2):273-279

7. Lv G et al (2015) Graphene oxide: a convenient metal-free carbocatalyst for facilitating aerobic oxidation of 5-hydroxymethylfurfural into 2, 5-diformylfuran. ACS Catal 5(9):5636-5646

8. ASTM Standards C618-89a (1989) ASTM Designation C61889a. Annual Book of ASTM Standards, p 289

9. Zhu Y et al (2010) Graphene and graphene oxide: synthesis, properties, and applications. Adv Mater 22(35):3906-3924

10. Geim AK, Novoselov KS (2007) The rise of graphene. Nat Mater 6(3):183-191

11. Morales Ibarra R et al (2020) Graphene exfoliation with supercritical fluids. Carbon Lett. https://doi.org/10.1007/s42823-02000153-x

12. Marinkas A et al (2013) Graphene as catalyst support: the influences of carbon additives and catalyst preparation methods on the performance of PEM fuel cells. Carbon 58:139-150

13. Chehroudi B (2016) Applications of graphene in fuel propellant combustion. In: Graphene science handbook, pp 391-398

14. Fan X (2015) Graphene: a promising two-dimensional support for heterogeneous catalysts. Front Mater 1(39):1-2

15. Hu L et al (2010) Density functional calculation of transition metal adatom adsorption on graphene. Phys B 405(16):3337-3341

16. Nakada K, Ishii A (2011) Migration of adatom adsorption on graphene using DFT calculation. Solid State Commun 151(1):13-16

17. Machado BF, Serp P (2012) Graphene-based materials for catalysis. Catal Sci Technol 2(1):54-75
18. Tang Y, Yang Z, Dai X (2011) Noble metals induced magnetic properties of graphene. J Magn Magn Mater 323(20):2441-2447

19. Yanwu $Z$ et al (2010) Graphene and graphene oxide: synthesis, properties, and applications. Adv Mater 22(35):3906-3924

20. Woo J-H et al (2019) Effect of polydopamine-modified reduced graphene oxides on the catalytic activity of Pt nanoparticles catalysts for fuel cell electrodes. Carbon Lett 29(1):47-55

21. Liu J et al (2018) Graphene-based nanomaterials and their potentials in advanced drug delivery and cancer therapy. J Control Release 286:64-73

22. Boukhvalov DW, Katsnelson MI (2009) Chemical functionalization of graphene. J Phys Condens Matter 21(34):344205

23. Hashimoto A et al (2004) Direct evidence for atomic defects in graphene layers. Nature 430:870

24. Fan X, Zhang G, Zhang F (2015) Multiple roles of graphene in heterogeneous catalysis. Chem Soc Rev 44(10):3023-3035

25. Shende P, Augustine S, Prabhakar B (2020) A review on graphene nanoribbons for advanced biomedical applications. Carbon Lett 30:465-475

26. Jeong $\mathrm{H}-\mathrm{S}$ et al (2020) Oriented wrinkle textures of free-standing graphene nanosheets: application as a high-performance lithiumion battery anode. Carbon Lett. https://doi.org/10.1007/s4282 3-020-00163-9

27. $\mathrm{Hu} \mathrm{H}$ et al (2015) Metal-free graphene-based catalyst-insight into the catalytic activity: a short review. Appl Catal A 492:1-9

28. Zhou X et al (2014) A review of graphene-based nanostructural materials for both catalyst supports and metal-free catalysts in PEM fuel cell oxygen reduction reactions. Adv Energy Mater 4(8): 1301523

29. Song C, Zhang J (2008) Electrocatalytic oxygen reduction reaction. In: Zhang J (ed) PEM fuel cell electrocatalysts and catalyst layers: fundamentals and applications. Springer, London, pp 89-134

30. Zhang L et al (2006) Progress in preparation of non-noble electrocatalysts for PEM fuel cell reactions. J Power Sour 156(2):171-182

31. Gouérec P, Savy M, Riga J (1998) Oxygen reduction in acidic media catalyzed by pyrolyzed cobalt macrocycles dispersed on an active carbon: the importance of the content of oxygen surface groups on the evolution of the chelate structure during the heat treatment. Electrochim Acta 43(7):743-753

32. Goellner V et al (2015) Degradation by hydrogen peroxide of metal-nitrogen-carbon catalysts for oxygen reduction. J Electrochem Soc 162(6):H403-H414

33. Higgins D et al (2016) The application of graphene and its composites in oxygen reduction electrocatalysis: a perspective and review of recent progress. Energy Environ Sci 9(2):357-390

34. Rabis A, Rodriguez P, Schmidt TJ (2012) Electrocatalysis for polymer electrolyte fuel cells: recent achievements and future challenges. ACS Catalysis 2(5):864-890

35. Shao M-H, Sasaki K, Adzic RR (2006) Pd-Fe nanoparticles as electrocatalysts for oxygen reduction. J Am Chem Soc 128(11):3526-3527

36. Carpenter MK et al (2012) Solvothermal synthesis of platinum alloy nanoparticles for oxygen reduction electrocatalysis. J Am Chem Soc 134(20):8535-8542

37. 황 성 주 One-pot synthesis of platinum nanoparticles embedded on reduced graphene oxide for oxygen reduction in methanol fuel cells. 14(7)

38. He W et al (2012) An efficient reduction route for the production of Pd-Pt nanoparticles anchored on graphene nanosheets for use as durable oxygen reduction electrocatalysts. Carbon 50(1):265-274

39. Zeng L et al (2015) Graphene-supported platinum catalyst prepared with ionomer as surfactant for anion exchange membrane fuel cells. J Power Sour 275:506-515 
40. Hsieh SH et al (2013) Study of Pt catalyst on graphene and its application to fuel cell. Appl Surf Sci 277:223-230

41. Li J et al (2016) Synthesis of PtM (M=Co, Ni)/reduced graphene oxide nanocomposites as electrocatalysts for the oxygen reduction reaction. Nanoscale Res Lett 11(1):3

42. Seger B, Kamat PV (2009) Electrocatalytically active grapheneplatinum nanocomposites. Role of 2-D carbon support in PEM fuel cells. J Phys Chem C 113(19):7990-7995

43. Deng D et al (2011) Size effect of graphene on electrocatalytic activation of oxygen. Chem Commun 47(36):10016-10018

44. Lester $\mathrm{E}$ et al (2018) A proposed biomass char classification system. Fuel 232:845-854

45. Daley PJ et al (2019) The impact of ash pellet characteristics and pellet processing parameters on ash fusion behaviour. Fuel 251:779-788

46. Jiang D-E, Sumpter BG, Dai S (2007) Unique chemical reactivity of a graphene nanoribbon's zigzag edge. J Chem Phys 126(13): 134701

47. Guo S, Sun S (2012) FePt nanoparticles assembled on graphene as enhanced catalyst for oxygen reduction reaction. J Am Chem Soc 134(5):2492-2495

48. Lijun Y et al (2011) Boron-doped carbon nanotubes as metal-free electrocatalysts for the oxygen reduction reaction. Angew Chem Int Ed 50(31):7132-7135

49. Yang $Z$ et al (2012) Sulfur-doped graphene as an efficient metal-free cathode catalyst for oxygen reduction. ACS Nano 6(1):205-211

50. Benson $\mathbf{J}$ et al (2014) Tuning the catalytic activity of graphene nanosheets for oxygen reduction reaction via size and thickness reduction. ACS Appl Mater Interfaces 6(22):19726-19736

51. Imran Jafri R, Rajalakshmi N, Ramaprabhu S (2010) Nitrogen doped graphene nanoplatelets as catalyst support for oxygen reduction reaction in proton exchange membrane fuel cell. J Mater Chem 20(34):7114-7117

52. Bai J et al (2013) Nitrogen-doped graphene as catalysts and catalyst supports for oxygen reduction in both acidic and alkaline solutions. Int J Hydrogen Energy 38(3):1413-1418

53. Chenzhen $\mathrm{Z}$ et al (2013) Synthesis of phosphorus-doped graphene and its multifunctional applications for oxygen reduction reaction and lithium ion batteries. Adv Mater 25(35):4932-4937

54. Quílez-Bermejo J, Morallón E, Cazorla-Amorós D (2020) Metalfree heteroatom-doped carbon-based catalysts for ORR: a critical assessment about the role of heteroatoms. Carbon 165:434-454

55. Jang AR et al (2018) Electrochemical and electrocatalytic reaction characteristics of boron-incorporated graphene via a simple spin-on dopant process. J Mater Chem A 6(17):7351-7356

56. Bo X, Guo L (2013) Ordered mesoporous boron-doped carbons as metal-free electrocatalysts for the oxygen reduction reaction in alkaline solution. Phys Chem Chem Phys 15(7):2459-2465

57. Zhao Y et al (2013) Can boron and nitrogen codoping improve oxygen reduction reaction activity of carbon nanotubes? J Am Chem Soc 135(4):1201-1204

58. Yao Z et al (2013) Two-step boron and nitrogen doping in graphene for enhanced synergistic catalysis. Angew Chem 52(11):3110-3116

59. Garcia AC, Gasparotto LH, Gomes JF, Tremiliosi-Filho G (2012) Straightforward synthesis of carbon-supported Ag nanoparticles and their application for the oxygen reduction reaction. Electrocatalysis 3(2):147-152

60. Soo LT et al (2016) Synthesis of silver/nitrogen-doped reduced graphene oxide through a one-step thermal solid-state reaction for oxygen reduction in an alkaline medium. J Power Sour 324:412-420

61. Jiang S, Zhu C, Dong S (2013) Cobalt and nitrogen-cofunctionalized graphene as a durable non-precious metal catalyst with enhanced ORR activity. J Mater Chem A 1(11):3593-3599
62. Liang Y et al (2012) Oxygen reduction electrocatalyst based on strongly coupled cobalt oxide nanocrystals and carbon nanotubes. J Am Chem Soc 134(38):15849-15857

63. Wu J et al (2012) Manganese oxide-graphene composite as an efficient catalyst for 4-electron reduction of oxygen in alkaline media. Electrochim Acta 75:305-310

64. Zhou R, Qiao SZ (2014) Silver/nitrogen-doped graphene interaction and its effect on electrocatalytic oxygen reduction. Chem Mater 26(20):5868-5873

65. Lin Z et al (2013) Simple preparation of nanoporous few-layer nitrogen-doped graphene for use as an efficient electrocatalyst for oxygen reduction and oxygen evolution reactions. Carbon 53:130-136

66. Sheng Z-H et al (2011) Catalyst-free synthesis of nitrogen-doped graphene via thermal annealing graphite oxide with melamine and its excellent electrocatalysis. ACS Nano 5(6):4350-4358

67. Deng D et al (2011) Toward N-doped graphene via solvothermal synthesis. Chem Mater 23(5):1188-1193

68. Hu C et al (2018) Functionalization of graphene materials by heteroatom-doping for energy conversion and storage. Prog Nat Sci Mater Int 28(2):121-132

69. Jiang L, Cui L, He X (2014) Cobalt-porphyrin noncovalently functionalized graphene as nonprecious-metal electrocatalyst for oxygen reduction reaction in an alkaline medium. J Solid State Electrochem 19(2):497-506

70. Shaojun $\mathrm{G}$ et al (2012) $\mathrm{Co} / \mathrm{CoO}$ nanoparticles assembled on graphene for electrochemical reduction of oxygen. Angew Chem Int Ed 51(47):11770-11773

71. Liang Y et al (2012) Covalent hybrid of spinel manganese-cobalt oxide and graphene as advanced oxygen reduction electrocatalysts. J Am Chem Soc 134(7):3517-3523

72. Sibul R et al (2020) Iron- and nitrogen-doped graphenebased catalysts for fuel cell application. ChemElectroChem 7:1739-1747

73. Sun M et al (2015) Graphene-based transition metal oxide nanocomposites for the oxygen reduction reaction. Nanoscale 7(4):1250-1269

74. Turner JA (1999) A realizable renewable energy future. Science 285(5428):687-689

75. World Commission on, E. and Development (1987) Our common future. Oxford University Press, Oxford

76. Zhu J, Zäch M (2009) Nanostructured materials for photocatalytic hydrogen production. Curr Opin Colloid Interface Sci 14:260-269

77. Liu $\mathrm{G}$ et al (2012) Engineering $\mathrm{TiO}_{2}$ nanomaterials for $\mathrm{CO}_{2}$ conversion/solar fuels. Sol Energy Mater Sol Cells 105:53-68

78. Suk Jang J, Gyu Kim H, Lee JS (2012) Heterojunction semiconductors: a strategy to develop efficient photocatalytic materials for visible light water splitting. Catal Today 185:270-277

79. Quanhua $X$ et al (2012) A novel photocatalyst LaOF: facile fabrication and photocatalytic hydrogen production. Catal Commun 27:21-25

80. Ahmad $\mathrm{H}$ et al (2015) Hydrogen from photo-catalytic water splitting process: a review. Renew Sustain Energy Rev 43:599-610

81. Jiang D et al (2001) Photoelectrochemical behaviour of methanol oxidation at nanoporous $\mathrm{TiO}_{2}$ film electrodes. J Photochem Photobiol A 144(2):197-204

82. Lee JS (2006) Photocatalytic water splitting under visible light with particulate semiconductor catalysts. Catal Surv Asia 9(4):217-227

83. Wang $X$ et al (2008) A metal-free polymeric photocatalyst for hydrogen production from water under visible light. Nat Mater 8:76

84. Liu G et al (2010) Unique electronic structure induced high photoreactivity of sulfur-doped graphitic C3N4. J Am Chem Soc 132(33):11642-11648 
85. Wu N et al (2010) Shape-enhanced photocatalytic activity of single-crystalline anatase $\mathrm{TiO}_{2}(101)$ nanobelts. J Am Chem Soc 132(19):6679-6685

86. Yu J et al (2009) Enhancement of photocatalytic activity of mesporous $\mathrm{TiO}_{2}$ powders by hydrothermal surface fluorination treatment. J Phys Chem C 113(16):6743-6750

87. Joung D et al (2010) Space charge limited conduction with exponential trap distribution in reduced graphene oxide sheets. Appl Phys Lett 97(9):093105

88. Jiang $X$ et al (2013) Graphene oxide as a chemically tunable 2-D material for visible-light photocatalyst applications. J Catal 299:204-209

89. Yeh T-F et al (2011) Graphite oxide with different oxygenated levels for hydrogen and oxygen production from water under illumination: the band positions of graphite oxide. J Phys Chem C 115(45):22587-22597

90. Loh K et al (2010) Graphene oxide as a chemically tunable platform for optical applications. Nat Chem 2:1015-1024

91. Krishnamoorthy K, Mohan R, Kim S-J (2011) Graphene oxide as a photocatalytic material. Appl Phys Lett 98(24):244101

92. Liu P et al (2012) Hybrid density functional study on $\mathrm{SrTiO}_{3}$ for visible light photocatalysis. Int J Hydrogen Energy 37(16):11611-11617

93. Fujishima A, Honda K (1972) Electrochemical photolysis of water at a semiconductor electrode. Nature 238(5358):37-38

94. Khalid NR, Ahmed E, Hong Z, Zhang Y, Ullah M, Ahmed M (2013) Graphene modified Nd/TiO2 photocatalyst for methyl orange degradation under visible light irradiation. Ceram Int 39(4):3569-3575

95. Xu Y, Gao S-P (2012) Band gap of C3N4 in the GW approximation. Int J Hydrogen Energy 37:11072-11080

96. Zhang $\mathrm{H}$ et al (2010) P25-graphene composite as a high performance photocatalyst. ACS Nano 4(1):380-386

97. Zhang Y et al (2010) Cytotoxicity effects of graphene and singlewall carbon nanotubes in neural phaeochromocytoma-derived PC12 Cells. ACS Nano 4(6):3181-3186

98. Sher Shah MSA et al (2012) Green synthesis of biphasic $\mathrm{TiO}_{2}$-reduced graphene oxide nanocomposites with highly enhanced photocatalytic activity. ACS Appl Mater Interfaces 4(8):3893-3901

99. Kudo A, Miseki Y (2009) Heterogeneous photocatalyst materials for water splitting. Chem Soc Rev 38(1):253-278

100. Joy J, Mathew J, George SC (2018) Nanomaterials for photoelectrochemical water splitting-review. Int J Hydrogen Energy 43(10):4804-4817

101. Khan I et al (2017) Sonochemical assisted synthesis of RGO/ $\mathrm{ZnO}$ nanowire arrays for photoelectrochemical water splitting. Ultrason Sonochem 37:669-675

102. Yusoff $\mathrm{N}$ et al (2015) Core-shell $\mathrm{Fe}_{3} \mathrm{O}_{4}-\mathrm{ZnO}$ nanoparticles decorated on reduced graphene oxide for enhanced photoelectrochemical water splitting. Ceram Int 41(3):5117-5128

103. Li Q et al (2011) Highly efficient visible-light-driven photocatalytic hydrogen production of CdS-cluster-decorated graphene nanosheets. J Am Chem Soc 133(28):10878-10884

104. $\mathrm{Ng}$ YH et al (2010) Reducing graphene oxide on a visible-light $\mathrm{BiVO}_{4}$ photocatalyst for an enhanced photoelectrochemical water splitting. J Phys Chem Lett 1(17):2607-2612

105. Iwase A et al (2011) Reduced graphene oxide as a solid-state electron mediator in Z-scheme photocatalytic water splitting under visible light. J Am Chem Soc 133(29):11054-11057

106. Neppolian B et al (2012) Graphene oxide based $\mathrm{Pt}-\mathrm{TiO}_{2}$ photocatalyst: ultrasound assisted synthesis, characterization and catalytic efficiency. Ultrason Sonochem 19(1):9-15

107. Thakur K, Kandasubramanian B (2019) Graphene and Graphene oxide-based composites for removal of organic pollutants: a review. J Chem Eng Data 64(3):833-867
108. Giri AS, Golder AK (2014) Fenton, photo-Fenton, $\mathrm{H}_{2} \mathrm{O}_{2}$ photolysis, and $\mathrm{TiO}_{2}$ photocatalysis for dipyrone oxidation: drug removal, mineralization, biodegradability, and degradation mechanism. Ind Eng Chem Res 53(4):1351-1358

109. Zhao $\mathrm{H}$ et al (2016) Hg0-temperature-programmed surface reaction and its application on the investigation of metal oxides for $\mathrm{Hg} 0$ capture. Fuel 181:1089-1094

110. Zhao D et al (2012) Enhanced photocatalytic degradation of methylene blue under visible irradiation on graphene@ $\mathrm{TiO}_{2}$ dyade structure. Appl Catal B 111-112:303-308

111. Yang $\mathrm{X}$ et al (2015) Fabrication of $\mathrm{P} 25 / \mathrm{Ag}_{3} \mathrm{PO}_{4} /$ graphene oxide heterostructures for enhanced solar photocatalytic degradation of organic pollutants and bacteria. Appl Catal B 166-167:231-240

112. Han $\mathrm{S}$ et al (2014) One-step hydrothermal synthesis of $2 \mathrm{D}$ hexagonal nanoplates of $\alpha-\mathrm{Fe}_{2} \mathrm{O}_{3} /$ graphene composites with enhanced photocatalytic activity. Adv Func Mater 24(36):5719-5727

113. Guo $\mathrm{S}$ et al (2013) Graphene oxide- $\mathrm{Fe}_{2} \mathrm{O}_{3}$ hybrid material as highly efficient heterogeneous catalyst for degradation of organic contaminants. Carbon 60:437-444

114. Liu $Y$ et al (2017) Enhanced catalytic degradation of methylene blue by $\alpha-\mathrm{Fe}_{2} \mathrm{O}_{3}$ /graphene oxide via heterogeneous photo-Fenton reactions. Appl Catal B 206:642-652

115. Guo $\mathrm{S}$ et al (2017) Graphene modified iron sludge derived from homogeneous Fenton process as an efficient heterogeneous Fenton catalyst for degradation of organic pollutants. Microporous Mesoporous Mater 238:62-68

116. Arshad A et al (2018) Graphene/ $\mathrm{Fe}_{3} \mathrm{O}_{4}$ nanocomposite: Interplay between photo-Fenton type reaction, and carbon purity for the removal of methyl orange. Ceram Int 44(3):2643-2648

117. Liu $\mathrm{Y}$ et al (2017) Aligned $\alpha-\mathrm{FeOOH}$ nanorods anchored on a graphene oxide-carbon nanotubes aerogel can serve as an effective Fenton-like oxidation catalyst. Appl Catal B 213:74-86

118. Dong $C$ et al (2018) Developing stretchable and graphene-oxidebased hydrogel for the removal of organic pollutants and metal ions. Appl Catal B 222:146-156

119. Bhatkhande DS, Pangarkar VG, Beenackers AACM (2002) Photocatalytic degradation for environmental applications - a review. J Chem Technol Biotechnol 77(1):102-116

120. Tsutsumi O (2005) Assessment of human contamination of estrogenic endocrine-disrupting chemicals and their risk for human reproduction. J Steroid Biochem Mol Biol 93(2):325-330

121. Feldman MD (1997) Editorial: estrogens from plastic - are we being exposed? Endocrinology 138(5):1777-1779

122. Mamoru N, Hisanori K, Hidehiko S (1999) HPLC analysis of dental resin composites components. J Biomed Mater Res 47(3):374-378

123. Jafari A, Abasabad R, Salehzadeh A (2009) Endocerine disrupting contaminants in water resources and sewage in Hamadan City of Iran. J Environ Health Sci Eng 6(2):89-96

124. Vandenberg LN et al (2007) Human exposure to bisphenol A (BPA). Reprod Toxicol 24(2):139-177

125. Kuramitz $\mathrm{H}$ et al (2001) Electrochemical oxidation of bisphenol A. Application to the removal of bisphenol A using a carbon fiber electrode. Chemosphere 45(1):37-43

126. Orimolade BO, Adekola FA, Adebayo GB (2018) Adsorptive removal of bisphenol A using synthesized magnetite nanoparticles. Appl Water Sci 8(1):46

127. Sun $\mathrm{H}$ et al (2012) Reduced graphene oxide for catalytic oxidation of aqueous organic pollutants. ACS Appl Mater Interfaces 4(10):5466-5471

128. Liang C, Wang Z-S, Bruell CJ (2007) Influence of pH on persulfate oxidation of TCE at ambient temperatures. Chemosphere 66(1):106-113

129. Du J et al (2016) Efficient activation of peroxymonosulfate by magnetic Mn-MGO for degradation of bisphenol A. J Hazard Mater 320:150-159 
130. Yao $\mathrm{Y}$ et al (2013) Facile synthesis of $\mathrm{Mn}_{3} \mathrm{O}_{4}$-reduced graphene oxide hybrids for catalytic decomposition of aqueous organics. Ind Eng Chem Res 52(10):3637-3645

131. Dewei $\mathrm{W}$ et al (2012) Facile synthesis of porous $\mathrm{Mn}_{3} \mathrm{O}_{4}$ nanocrystal-graphene nanocomposites for electrochemical supercapacitors. Eur J Inorg Chem 2012(4):628-635

132. Krishna R, Sie ST (2000) Design and scale-up of the FischerTropsch bubble column slurry reactor. Fuel Process Technol 64:73-105

133. Davis BH (2005) Fischer-Tropsch synthesis: overview of reactor development and future potentialities. Top Catal 32(3/4):143-168

134. De Deugd RM (2004) Fischer-Tropsch synthesis revisited; efficiency and selectivity benefits from imposing temporal and/or spatial structure in the reactor, in DelftChemTech

135. Loosdrecht J, Botes FG, Ciobica IM, Ferreira AC, Gibson P, Moodley DJ, Saib AM, Visagie JL, Weststrate CJ, Niemantsverdriet JW (2013) Fischer-Tropsch synthesis: catalysts and chemistry. Surf Inorg Chem Heterog Catal 7(20):6200

136. Jahangiri $\mathrm{H}$ et al (2014) A review of advanced catalyst development for Fischer-Tropsch synthesis of hydrocarbons from biomass derived syn-gas. Catal Sci Technol 4(8):2210-2229

137. Mahmoudi $\mathrm{H}$ et al (2017) A review of Fischer Tropsch synthesis process, mechanism, surface chemistry and catalyst formulation. Biofuels Eng 2(1):11-31

138. Pang CH, Lester E, Wu T (2018) Influence of lignocellulose and plant cell walls on biomass char morphology and combustion reactivity. Biomass Bioenergy 119:480-491

139. Yan $J$ et al (2016) Influence of minerals on the thermal processing of bamboo with a suite of carbonaceous materials. Fuel 180:256-262

140. Schulz H (1999) Short history and present trends of FischerTropsch synthesis. Appl Catal A 186(1):3-12

141. Qinghong Z, Jincan K, Ye W (2010) Development of novel catalysts for Fischer-Tropsch synthesis: tuning the product selectivity. ChemCatChem 2(9):1030-1058

142. Davis BH (2007) Fischer-Tropsch synthesis: comparison of performances of iron and cobalt catalysts. Ind Eng Chem Res 46(26):8938-8945

143. Torres Galvis HM et al (2012) Supported iron nanoparticles as catalysts for sustainable production of lower olefins. Science 335(6070):835

144. Parvez AM et al (2016) Effect of the addition of different waste carbonaceous materials on coal gasification in $\mathrm{CO}_{2}$ atmosphere. Fuel Process Technol 149:231-238

145. Moussa SO et al (2014) Graphene-supported, iron-based nanoparticles for catalytic production of liquid hydrocarbons from synthesis gas: the role of the graphene support in comparison with carbon nanotubes. ACS Catal 4(2):535-545
146. Wei Y et al (2018) Enhanced Fischer-Tropsch performances of graphene oxide-supported iron catalysts via argon pretreatment. Catal Sci Technol 8(4):1113-1125

147. Zhao $\mathrm{H}$ et al (2020) $\mathrm{MoO}_{3}$-adjusted $\delta-\mathrm{MnO}_{2}$ nanosheet for catalytic oxidation of $\mathrm{Hg} 0$ to $\mathrm{Hg}^{2+}$. Appl Catal B 263:117829

148. Zhao HB et al (2013) Iron oxide nanoparticles supported on pyrolytic graphene oxide as model catalysts for Fischer Tropsch synthesis. Appl Catal A 456:233-239

149. Chen Q et al (2018) Design of ultra-active iron-based FischerTropsch synthesis catalysts over spherical mesoporous carbon with developed porosity. Chem Eng J 334:714-724

150. Nasser ALH et al (2018) Mn-Fe nanoparticles on a reduced graphene oxide catalyst for enhanced olefin production from syngas in a slurry reactor. RSC Adv 8(27):14854-14863

151. Dad $\mathrm{M}$ et al (2017) $\mathrm{SiO}_{2}$-supported $\mathrm{Fe} \& \mathrm{FeMn}$ colloids-Fischer-Tropsch synthesis on 3D model catalysts. Appl Catal A 537:83-92

152. Herranz T et al (2006) Synthesis, structural features, and reactivity of $\mathrm{Fe}-\mathrm{Mn}$ mixed oxides prepared by microemulsion. Chem Mater 18(9):2364-2375

153. Lohitharn N, Goodwin JG, Lotero E (2008) Fe-based FischerTropsch synthesis catalysts containing carbide-forming transition metal promoters. J Catal 255(1):104-113

154. Cheng Y et al (2016) Fischer-Tropsch synthesis to lower olefins over potassium-promoted reduced graphene oxide supported iron catalysts. ACS Catal 6(1):389-399

155. Hassan HMA et al (2009) Microwave synthesis of graphene sheets supporting metal nanocrystals in aqueous and organic media. J Mater Chem 19(23):3832-3837

156. Karimi $S$ et al (2015) Cobalt supported on Graphene-a promising novel Fischer-Tropsch synthesis catalyst. Appl Catal A 499:188-196

157. Karimi S et al (2015) Enhancement of cobalt catalyst stability in Fischer-Tropsch synthesis using graphene nanosheets as catalyst support. Chem Eng Res Des 104:713-722

158. Taghavi S, Asghari A, Tavasoli A (2017) Enhancement of performance and stability of Graphene nano sheets supported cobalt catalyst in Fischer-Tropsch synthesis using graphene functionalization. Chem Eng Res Des 119:198-208

Publisher's Note Springer Nature remains neutral with regard to jurisdictional claims in published maps and institutional affiliations. 